\title{
Vibration control in buildings under seismic excitation using optimized tuned mass dampers
}

\author{
Francisco da Silva Brandão \\ PPGEC/UFRGS and Centro Universitário Ritter dos Reis - UniRitter, Brazil \\ eng.fsbrandao@gmail.com, https://orcid.org/0000-0001-7888-6321 \\ Letícia Fleck Fadel Miguel \\ Department of Mechanical Engineering, Federal University of Rio Grande do Sul, Brazil \\ letffm@ufrgs.br, bttps://orcid.org/0000-0001-9165-4306
}

\begin{abstract}
Earthquakes can cause vibration problems in many types of structures, generating large displacements. The interstory drift is a design criterion very used in seismic analysis and the structural control is an alternative to reduce these displacements and improve the performance of these structures adapting them to the imposed criteria. TMD is a device widely used due to the simple principle of operation and many successful applications in real life practice. This paper investigates the use of optimized TMD for reduction of maximum horizontal displacement at the top floor and interstory drift of a steel building under seismic excitation considering three scenarios: single TMD at the top floor; MTMD horizontally arranged at the top floor; and MTMD vertically arranged on the structure. By a metaheuristic optimization algorithm, the parameters and positions of the devices are obtained. Three real and one artificial earthquakes are employed in the simulations. The results showed that all proposed scenarios are efficient in reducing top floor response and interstory drift to values below of the interstory drift limits allowed by the standard code consulted. However, Scenario 2 presented the best reduction for the top displacement and interstory drift to the critical floor for the worst earthquake considered.
\end{abstract}

KEYWORDS. TMD; Vibration control; Optimization; Whale Optimization Algorithm; Interstory drift.

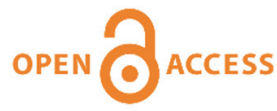

Citation: Brandão, F. S., Miguel, L. F. F. Vibration control in buildings under seismic excitation using optimized tuned mass dampers, Frattura ed Integrità Strutturale, 54 (2020) 66-87.

Received: 27.05.2020

Accepted: 12.08 .2020

Published: 01.10 .2020

Copyright: (C) 2020 This is an open access article under the terms of the CC-BY 4.0, which permits unrestricted use, distribution, and reproduction in any medium, provided the original author and source are credited.

\section{INTRODUCTION}

$\mathrm{E}$ arthquakes are a natural phenomenon with violent shaking of the ground due to tectonic movements in the interior of the earth [1]. When the structure is subjected to seismic excitation there is an induction of horizontal forces at foundation level of structures which can generate vibration problems and in situations where the frequency of this excitation is very close to some natural frequency of the structure, the vibrations can reach large amplitude, allowing which the resonance phenomenon can occur, which can cause large displacements in the structure, and even its collapse [2-4]. In this scenario, the structural control is an alternative to reduce the levels of vibrations and 
improve the performance of these structures when requested by dynamics actions. In general, the control devices used in structural control can be classified in three main groups, namely: passive, active and semi-active control devices. Passive control devices do not require external power source for operation and utilize the motion of the structure to dissipate the energy generated by the dynamic action, such as viscous damper, friction damper and the Tuned Mass Dampers (TMD) [5], which is focus of this work. Regarding the use of viscous damper, an interesting study is presented by [6] where two search methods based on the genetic algorithms are adopted to examine the optimal distribution of damping coefficients for viscous dampers in buildings under three different earthquake records. In the work presented by [7], a new methodology for the simultaneous optimization of placement and forces of friction dampers for buildings subjected to seismic loads, was proposed. A six-story shear building was analyzed, and a metaheuristic algorithm was utilized to solve the proposed problem.

For the active control devices, differently passive system, require the application of external power source for operation and are operated by hydraulic or electromechanical actuators and the force control is monitored by sensors that detect the response of the structure and the extent of external action [5]. A typical example is the Active Mass Damper (AMD), such as utilized by [8] to analyze the response of two different building under seismic excitations. The main aim of their work was the development of a method for achieving the vibrations control in buildings utilizing a limited number of floors equipped with active controlled dampers. In the work of [9], an AMD consisting of an AC servo motor, a movable mass connected to the AC servo motor and an accelerometer, was utilized to reduces the dynamic response of structures subjected to earthquake load. The authors proposed the Negative Acceleration Feedback (NAF) control algorithm for the proposed AMD system. The effectiveness of the control system was first evaluated using a Single-Degree-of-Freedom (SDOF) system and then for Multi-Degree-of-Freedom (MDOF) systems using a single AMD by the Multi-Modal NAF (MMNAF) control, which was validated in laboratory.

Finally, the semi-active control devices can be understood as an intermediate system among the active and passive system, because they require a small external power source for operation and utilize the motion of structure to generate control forces [5]. An application of these devices can be found in the study of [10] where an improved Displacement SemiActive Hydraulic Damper (DSHD), by converting it to Active Interaction Control Device (AIC) with the addition of an accumulator, was utilized to minimize the dynamic response of a building under earthquakes. The authors tested a prototype in laboratory using full-scale elements and evaluating the structural displacement and typical responses of the interacting interface element proposed. In [11] a simple and effective method for optimal control of structures using the magnetorheological dampers (MRD) is proposed. The effectiveness and performance of the proposed method were evaluated by simulating the response of a structure subjected to real seismic excitations.

Among the many types of passive vibration control systems, the TMD is the most popular due to its simple principle and the many successful applications in real life practice. The use of vibration absorbers dates to 1909 when it was first studied by Frahm. The researcher proposed a kind of TMD applied to a main spring-mass without damping which was attached to a small spring-mass without damping to reduce the displacement of the main mass subjected to harmonic load [12-13]. The classical TMD system consists of a mass, an elastic spring and a viscous (or hysteretic) damper and its parameters have a direct effect on the response of the main structural system. Therefore, tuning the parameters of TMDs constitutes one of the most important stages in a structural control system project [14].

The passive system using TMD is an extremely useful type of control for mitigating natural hazards and enhancing the safety and serviceability of structural systems. As these devices do not require an external power source for operation and they utilize the motion of the structure to develop the control forces, they are cheaper and simpler than active and semiactive control devices, for example, and, consequently, they are broadly used in structures around the world [7]. For a structure equipped with single TMD, the device should generally be installed at the top of the structure and its natural frequency is tuned around the frequency of the fundamental mode, which has the most influence on the response of the structure, so when the structure vibrates, the TMD vibrates with the same frequency and absorbs part of the energy from the main system [15-16].

In this process, a single TMD can perform well in reducing the dynamics response of a structure under external excitation. However, this can be a disadvantage, because the TMD may present low performance in the control of the upper vibration modes of the structure [17-18]. A simple solution to overcome these shortcomings is the installation of Multiple Tuned Mass Dampers (MTMD) which can be tuned to different modes and placed at many locations of the structure to enhance its performance. The performance of MTMD depends on their parameters such as mass, stiffness, and damping. However, determining the number of devices to be installed and the best position in the structure, as well as optimum parameters in terms of spring stiffness and damping constant for each TMD, is an optimization problem of great interest to the engineer designer and can be solved by optimization algorithms, which are used to minimize an objective function and to find an optimal solution of the problem [18]. 
Overall, the optimization process seeks to minimize or maximize a given function which this may be subject to equality, inequality or lateral restrictions, in order to obtain maximum efficiency for a pre-established measure. Optimization is one of the most studied fields in the wide field of artificial intelligence. Hundreds of studies published year after year focus on solving many diverse problems by resorting to a vast spectrum of solvers [19].

The metaheuristic algorithms have excelled in solving optimization problems, mainly because they do not use the gradient value of the objective function. Most of these are nature inspired, for example, in the movement of swarm members in Particle Swarm Optimization (PSO) [20]; the behavior of ants seeking a path between colony and food in Ant Colony Optimization (ACO) [21]; by the observation which the aim of music is to search for a perfect state of harmony in Harmony Search (HS) [22]; the flashing behavior of fireflies in Firefly Algorithm (FA) [23]; the hunting strategy of humpback whales in Whale Optimization Algorithm (WOA) [24]; which was used in this paper.

Many types of dynamic problem are solved by a metaheuristic optimization algorithm, for example, for optimization of TMD, as shown in work of [12] where the authors used the Charged System Search (CSS) [25], an algorithm based on the laws electrostatics and Newtonian mechanics, to find the optimum parameters of single TMD to minimize the dynamic response of multi-story building systems under seismic excitations.

In [14], authors used an algorithm called Cuckoo Search (CS) [26] based on the obligate brood parasitic behavior of some cuckoo species in combination with the Levy flight behavior of some birds and fruit flies, to find the optimum parameters of a single TMD for buildings under seismic excitations through a new multi-objective optimization method.

To design of MTMD, in a specific scenario of the work of [27] a hybrid formulation with two algorithms, Firefly Algorithm and Nelder-Mead Algorithm, a non-derivative search method for multidimensional unconstrained minimization developed by [28], was used to the global optimization of multiple tuned mass dampers for structures subjected to seismic excitations taking into account the oscillators' vertical and horizontal distribution. According to the authors, this procedure is extremely useful because it avoids the pre-definition of the tuned mass dampers number and their placement. In the study presented by [29], the true optimal of individual stiffness and damping parameters of MTMD system was obtained using an optimization algorithm, namely, artificial bee colony (ABC) algorithm [30] which simulates a particular intelligent behavior of a honey bee swarm, foraging behavior, and a new artificial bee colony for solving multidimensional and multimodal optimization problems. In their study, parameters of TMD units are treated as free search optimization variables and the $\mathrm{ABC}$ algorithm, which is powerful enough to handle a large number of design variables, has been utilized in obtaining optimum parameters of MTMDs.

In the work of [18] a new methodology for simultaneous optimization of parameters and positions of MTMD in buildings subjected to earthquakes is proposed, where they consider uncertainties present in the structural parameters, in the dynamic load, and also in the MTMD design with the aim of obtaining a robust optimum design. To solve the optimization problem, the Search Group Algorithm (SGA) [31] an efficient metaheuristic algorithm in which the main goal is to be balanced in terms of exploration and exploitation of the design domain, was used. Consequently, the SGA aims at providing better designs than other metaheuristics for the same computational cost.

Vibration control of structures under seismic excitation is an interesting field of research and linked to structural optimization of TMD plays an important role in mitigating the impacts of earthquakes on structures. In this context, this paper presents a study on the use of optimized TMD for reduction of the maximum horizontal displacement at the top floor and also the interstory drift of a steel building under seismic excitation in three scenarios: single TMD at the top floor (Scenario 1); MTMD horizontally arranged at the top floor (Scenario 2); and MTMD vertically arranged on the structure (Scenario 3). Three real and one artificial earthquakes are employed in the simulations. To evaluating of the maximum interstory drift, the ANSI/AISC 360-16 code of the American Institute of Steel Construction [32] are considered and in order to obtain the optimized devices in each scenario, a metaheuristic optimization algorithm, denominated Whale Optimization Algorithm (WOA) is utilized to find the optimal parameters (spring and damping constants) for each TMD and also, the optimal TMD position for MTMD in Scenario 3.

\section{EQUATION OF MOTION FOR A LINEAR STRUCTURE UNDER SEISMIC EXCITATION EQUIPPED WITH TMD}

7 he differential equation of motion of a n-degree-of-freedom (n-DOF) system with linear behavior for material and equipped with one TMD at the top floor (Fig. 1.a) or with MTMD possibly located in all floors of the structure (Fig. 1.b) and subjected to earthquake ground motion, may be written as:

$$
\mathbf{M} \overrightarrow{\ddot{u}}(t)+\mathbf{K} \overrightarrow{\dot{u}}(t)+\mathbf{C} \vec{u}(t)=-\mathbf{M B} \overrightarrow{\ddot{u}}_{g}(t)
$$


In which $\mathbf{M}, \mathbf{C}$ and $\mathbf{K}$ represent the $\left(n+N_{T M D}\right) x\left(n+N_{T M D}\right)$ mass, stiffness and damping matrices and $n$ is the number of degrees of freedom. The damping matrix $\mathbf{C}$ is assumed to be proportional to the $\mathbf{M}$ and $\mathbf{K}$ matrices as: $\mathbf{C}=\alpha \mathbf{M}+\beta \mathbf{K}$. $\overrightarrow{\ddot{u}}(t), \quad \overrightarrow{\dot{u}}(t), \quad \vec{u}(t)$, are the $\left(n+N_{T M D}\right)$-dimensional acceleration, velocity and displacement vectors relative to ground, respectively. The matrix $\mathbf{B}$ is a $\left(n+N_{T M D}\right) x d$ matrix that contains the cosine directors of the angles formed between the base motion and the associated displacement direction with the considered degree of freedom and $d$ is the number of considered ground motions (directions). $\overrightarrow{\ddot{u}}_{g}(t)$, represents the base acceleration and is a $d$-dimensional vector.

(a)

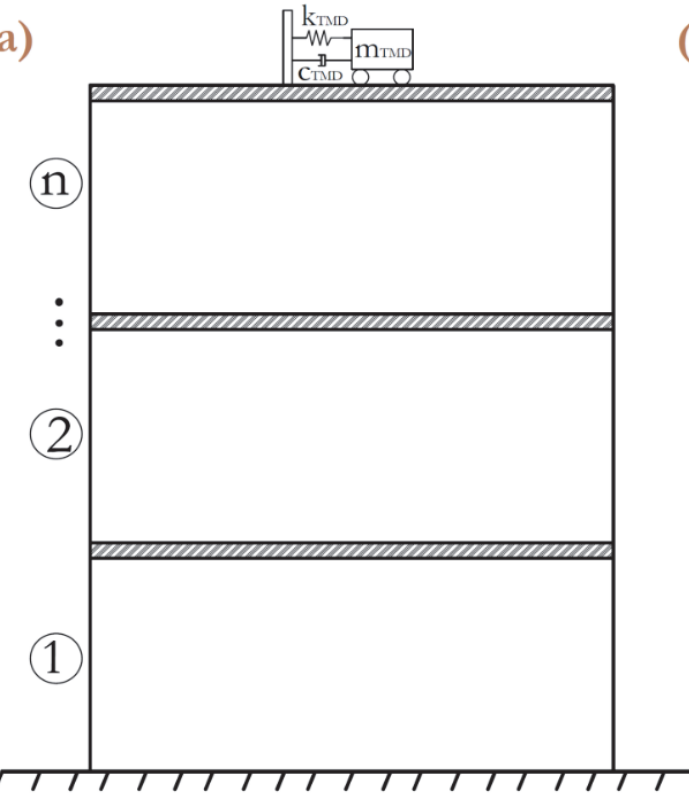

(b)

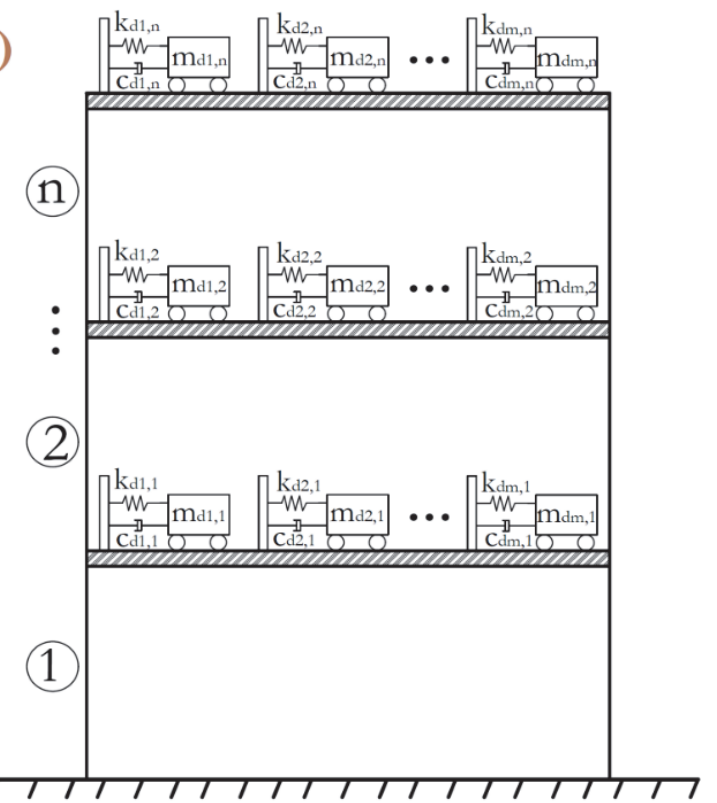

Figure 1: n-degree-of-freedom system (n-DOF) structure equipped (a) with one TMD at the top floor and (b) with MTMD possibly located in all floors of the structure.

In Fig. 1.(a), there is a single TMD attached at the top floor of the structure. The structure DOF is increased by one and the TMD contribution to $\mathbf{M}$ and $\mathbf{K}$, is illustrated in Eqns. 2 and 3. For the $\mathbf{C}$ matrix, the procedure is analogous to the $\mathbf{K}$.

$$
\begin{aligned}
\mathbf{M} & =\left[\begin{array}{ccccc}
m_{1} & 0 & \cdots & 0 & 0 \\
0 & m_{2} & \cdots & 0 & 0 \\
\vdots & \vdots & \ddots & \vdots & \vdots \\
0 & 0 & \cdots & m_{n} & 0 \\
0 & 0 & \cdots & 0 & m_{T M D}
\end{array}\right] \\
\mathbf{K} & =\left[\begin{array}{ccccc}
k_{1}+k_{2} & -k_{2} & \cdots & 0 & 0 \\
-k_{2} & k_{2}+k_{3} & \cdots & 0 & 0 \\
\vdots & \vdots & \ddots & \vdots & \vdots \\
0 & 0 & \cdots & k_{n}+k_{T M D} & -k_{T M D} \\
0 & 0 & \cdots & -k_{T M D} & k_{T M D}
\end{array}\right]
\end{aligned}
$$

Fig. 1.(b) represents the MTMD possibly located on all floors of the structure, the TMD contribution to $\mathbf{M}$ and $\mathbf{K}$ is illustrated in Eqns. 4 and 5. Again, for the $\mathbf{C}$ matrix, the procedure is analogous to the $\mathbf{K}$. 


$$
\mathbf{M}=\left[\begin{array}{ccccccccccccccccc}
m_{1} & 0 & \cdots & 0 & 0 & 0 & \cdots & 0 & 0 & 0 & \cdots & 0 & \cdots & 0 & 0 & \cdots & 0 \\
0 & m_{2} & \cdots & 0 & 0 & 0 & \cdots & 0 & 0 & 0 & \cdots & 0 & \cdots & 0 & 0 & \cdots & 0 \\
\vdots & \vdots & \ddots & \vdots & \vdots & \vdots & \cdots & \vdots & \vdots & \vdots & \cdots & \vdots & \cdots & \vdots & \vdots & \cdots & \vdots \\
0 & 0 & \cdots & m_{n} & 0 & 0 & \cdots & 0 & 0 & 0 & \cdots & 0 & \cdots & 0 & 0 & \cdots & 0 \\
0 & 0 & \cdots & 0 & m_{d 1,1} & 0 & \cdots & 0 & 0 & 0 & \cdots & 0 & \cdots & 0 & 0 & \cdots & 0 \\
0 & 0 & \cdots & 0 & 0 & m_{d 2,1} & \cdots & 0 & 0 & 0 & \cdots & 0 & \cdots & 0 & 0 & \cdots & 0 \\
\vdots & \vdots & \cdots & \vdots & \vdots & \vdots & \ddots & \vdots & \vdots & \vdots & \cdots & \cdots & \cdots & \vdots & \vdots & \cdots & \vdots \\
0 & 0 & \cdots & 0 & 0 & 0 & \cdots & m_{d m, 1} & 0 & 0 & \cdots & 0 & \cdots & 0 & 0 & \cdots & 0 \\
0 & 0 & \cdots & 0 & 0 & 0 & \cdots & 0 & m_{d 1,2} & 0 & \cdots & 0 & \cdots & 0 & 0 & \cdots & 0 \\
0 & 0 & \cdots & 0 & 0 & 0 & \cdots & 0 & 0 & m_{d 2,2} & \cdots & 0 & \cdots & 0 & 0 & \cdots & 0 \\
\vdots & \vdots & \cdots & \vdots & \vdots & \vdots & \cdots & \vdots & \vdots & \vdots & \ddots & \vdots & \cdots & \vdots & \vdots & \cdots & \vdots \\
0 & 0 & \cdots & 0 & 0 & 0 & \cdots & 0 & 0 & 0 & \cdots & m_{d m, 2} & \cdots & 0 & 0 & \cdots & 0 \\
\vdots & \vdots & \cdots & \vdots & \vdots & \vdots & \cdots & \vdots & \vdots & \vdots & \cdots & \vdots & \ddots & \vdots & \vdots & \cdots & \vdots \\
0 & 0 & \cdots & 0 & 0 & 0 & \cdots & 0 & 0 & 0 & \cdots & 0 & \cdots & m_{d 1, n} & 0 & \cdots & 0 \\
0 & 0 & \cdots & 0 & 0 & 0 & \cdots & 0 & 0 & 0 & \cdots & 0 & \cdots & 0 & m_{d 2, n} & \cdots & 0 \\
\vdots & \vdots & \cdots & \vdots & \vdots & \vdots & \cdots & \vdots & \vdots & \vdots & \cdots & \vdots & \cdots & \vdots & \vdots & \ddots & \vdots \\
0 & 0 & \cdots & 0 & 0 & 0 & \cdots & 0 & 0 & 0 & \cdots & 0 & \cdots & 0 & 0 & \cdots & m_{d m, n}
\end{array}\right](4)
$$

where $m_{n}, c_{n}$, and $k_{n}$ represent the mass, damping coefficient, and stiffness of the $n^{\text {th }}$ story of the structure, respectively. Also, $m_{d i}, c_{d i}, k_{d i}(i=1,2,3, \ldots, m)$ where $m$ is the last TMD in each floor considering horizontal distribution, are the mass, damping coefficient and stiffness of $i^{t h}$ TMD, respectively. To solve Eq. 1, a numerical integration method can be applied.

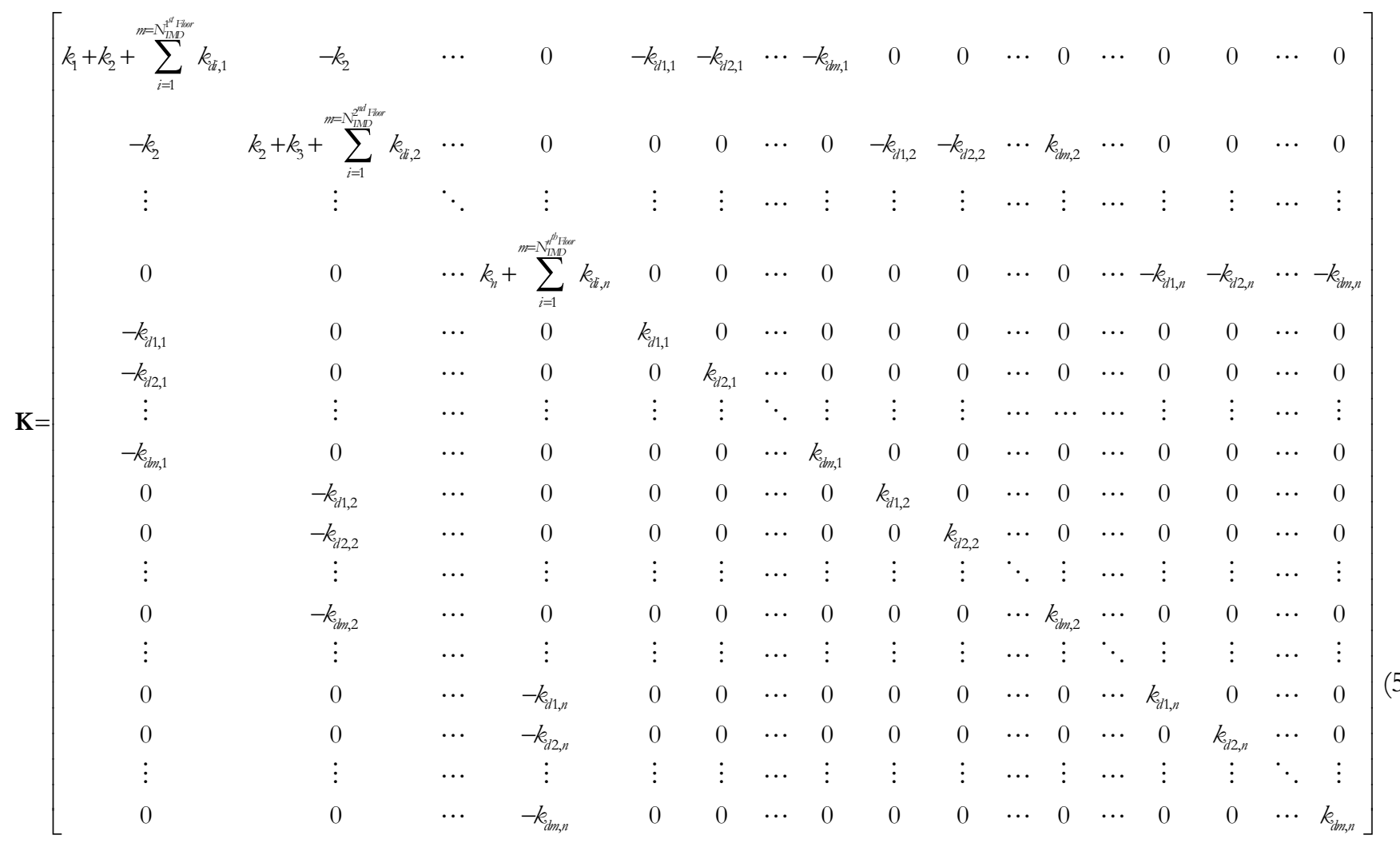




\section{Proposed METHOdology}

\section{Analyzed structure}

T $\mathrm{n}$ this study, a 2D building (Fig. 2) with structure predominantly in steel adapted from [33] is utilized. The building consists of 10 floors, where the height of the first and second floor are $3.65 \mathrm{~m}$ and $5.49 \mathrm{~m}$, respectively. The remaining floors have a height of $3.96 \mathrm{~m}$, which totals $40.82 \mathrm{~m}$. The base has five spans of $9.15 \mathrm{~m}$ each, totaling $45.75 \mathrm{~m}$ in length. Fig. 2 (a) shows the building with dimensions and profiles used, while Fig. 2 (b) shows the numbering of nodes and the bars. The building has 66 nodes with 3 DOF each, totaling 198 DOF, 110 elements and the base nodes that correspond to nodes 1 to 6 are fixed in the ground.

(a)

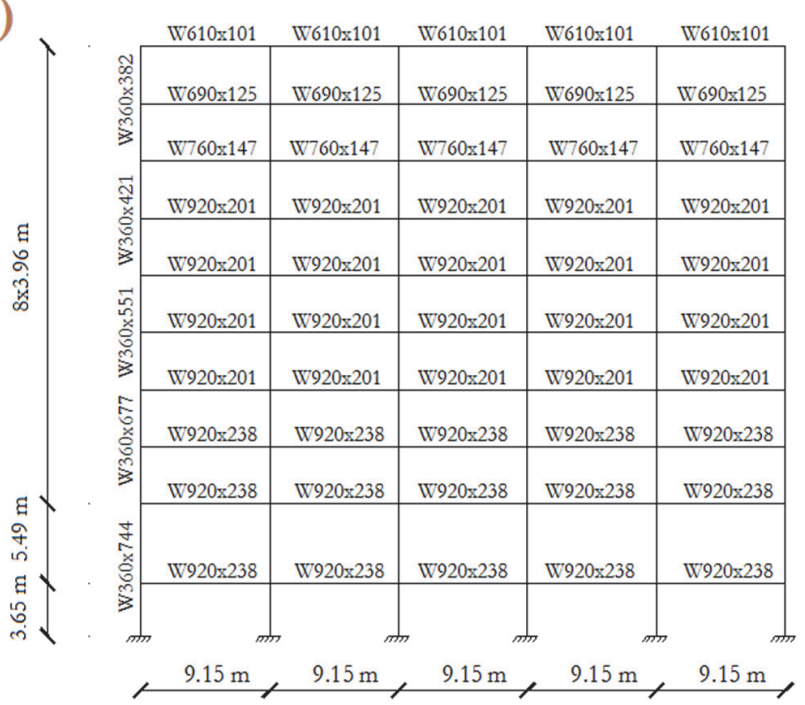

(b)

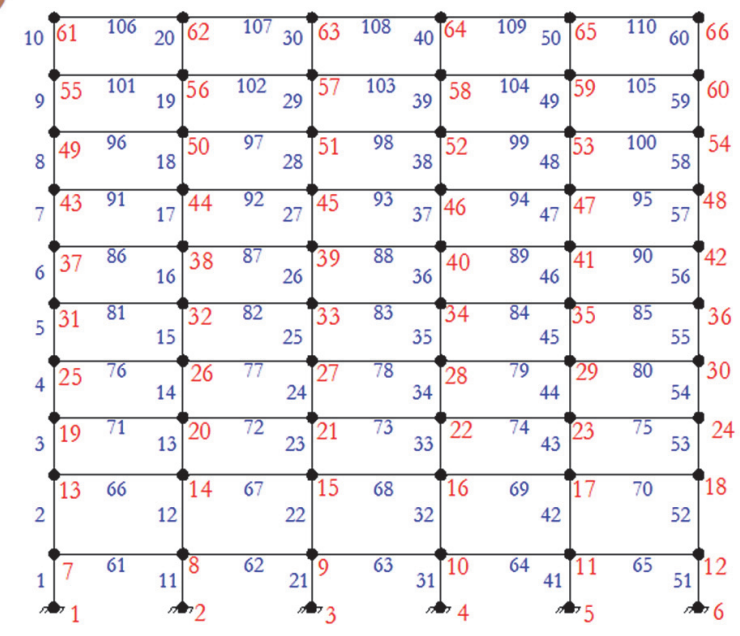

Figure 2: 2D Steel building: (a) W shape of structural elements and dimensions; (b) numbering of nodes and bars.

Considering that the structure of the building is predominantly in steel, for all 110 elements of the structure, the properties of the material $E=200 \mathrm{GPa}, \rho=7850 \mathrm{~kg} / \mathrm{m}^{3}$ and $\nu=0.3$ were attributed. The other properties required for the analysis, Inertia Moment, I, and cross-sectional area, $\mathrm{A}$, are shown in Tab. 1:

\begin{tabular}{|c|c|c|c|c|}
\hline W Shape & Member number & Area $\left(\mathrm{m}^{2}\right)$ & Inertia moment $\left(\mathrm{m}^{4}\right)$ & Structural Element type \\
\hline W360x744 & $1,2,11,12,21,22,31,32,41,42,51,52$ & $9.48 \times 10^{-2}$ & $3.42 \times 10^{-3}$ & \multirow{5}{*}{ Column } \\
\hline W360x677 & $3,4,13,14,23,24,33,34,43,44,53,54$ & $8.65 \times 10^{-2}$ & $2.99 \times 10^{-3}$ & \\
\hline W360x 551 & $5,6,15,16,25,26,35,36,45,46,55,56$ & $7.03 \times 10^{-2}$ & $2.26 \times 10^{-3}$ & \\
\hline W360x421 & $7,8,17,18,27,28,37,38,47,48,57,58$ & $5.37 \times 10^{-2}$ & $1.60 \times 10^{-3}$ & \\
\hline W360x382 & $9,10,19,20,29,30,39,40,49,50,59,60$ & $4.88 \times 10^{-2}$ & $1.42 \times 10^{-3}$ & \\
\hline W920x238 & $\begin{array}{c}61,62,63,64,65,66,67,68,69,70,71,72 \\
73,74,75\end{array}$ & $3.03 \times 10^{-2}$ & $4.06 \times 10^{-3}$ & \multirow{5}{*}{ Beam } \\
\hline W920x201 & $\begin{array}{c}76,77,78,79,80,81,82,83,84,85,86,87 \\
88,89,90,91,92,93,94,95\end{array}$ & $2.56 \times 10^{-2}$ & $3.25 \times 10^{-3}$ & \\
\hline W760x147 & $96,97,98,99,100$ & $1.88 \times 10^{-2}$ & $1.66 \times 10^{-3}$ & \\
\hline W690x125 & $101,102,103,104,105$ & $1.60 \times 10^{-2}$ & $1.19 \times 10^{-3}$ & \\
\hline W610x101 & $106,107,108,109,110$ & $1.30 \times 10^{-2}$ & $7.62 \times 10^{-4}$ & \\
\hline
\end{tabular}

Table 1: Properties of structural elements of 2D steel building. 
The structure was modeled in Matlab software using a 2D frame element flat with 2 nodes and 3 DOF for each node. This finite element has one horizontal translation, one vertically translation and one rotation in the plane for each node. The mass matrix of the structure is consistent where for each element, the mass and stiffness matrix in the local system, is represented by $\mathbf{M}^{\mathrm{e}}$ and $\mathbf{K}^{\mathrm{e}}$.

$$
\begin{aligned}
& \mathbf{M}^{e}=\frac{\rho A L}{420}\left[\begin{array}{cccccc}
140 & 0 & 0 & 70 & 0 & 0 \\
0 & 156 & 22 L & 0 & 54 & -13 L \\
0 & 22 L & 4 L^{2} & 0 & 13 L & -3 L^{2} \\
70 & 0 & 0 & 140 & 0 & 0 \\
0 & 54 & 13 L & 0 & 156 & -22 L \\
0 & -13 L & -3 L^{2} & 0 & -22 L & 4 L^{2}
\end{array}\right] \\
& \mathbf{K}^{e}=\left[\begin{array}{cccccc}
\frac{E A}{L} & 0 & 0 & -\frac{E A}{L} & 0 & 0 \\
0 & \frac{12 E I}{L^{3}} & \frac{6 E I}{L^{2}} & 0 & -\frac{12 E I}{L^{3}} & \frac{6 E I}{L^{2}} \\
0 & \frac{6 E I}{L^{2}} & \frac{4 E I}{L} & 0 & -\frac{6 E I}{L^{2}} & \frac{2 E I}{L} \\
-\frac{E A}{L} & 0 & 0 & \frac{E A}{L} & 0 & 0 \\
0 & -\frac{12 E I}{L^{3}} & -\frac{6 E I}{L^{2}} & 0 & \frac{12 E I}{L^{3}} & -\frac{6 E I}{L^{2}} \\
0 & \frac{6 E I}{L^{2}} & \frac{2 E I}{L} & 0 & -\frac{6 E I}{L^{2}} & \frac{4 E I}{L}
\end{array}\right]
\end{aligned}
$$

Through a code developed in Matlab which reads an input file with the coordinates of each node, the connectivity between the elements, the properties of the cross-section and material the assembly of the global mass and stiffness matrices of the structure was performed. After reading this file, the eigenvalues and eigenvectors which represent the building's natural frequencies and vibration modes are calculated. The first ten natural frequencies of the building are: $2.4745 \mathrm{~Hz} ; 6.4281 \mathrm{~Hz} ; 10.8511 \mathrm{~Hz} ; 16.5136 \mathrm{~Hz} ; 22.6422 \mathrm{~Hz} ; 26.9282 \mathrm{~Hz} ; 27.9586 \mathrm{~Hz} ; 28.6196 \mathrm{~Hz} ; 29.6882$ Hz; 31.9920 $\mathrm{Hz}$; . In Fig. 3 are shown the first three mode shapes. For the building damping matrix, a Rayleigh Damping Matrix ( $\mathbf{C}=\alpha \mathbf{M}+\beta \mathbf{K})$ was used which is given by the linear combination of the mass and stiffness matrices. Since the critical damping ratio, $\zeta$, considered in this analysis equal to $1 \%$ for the first two vibration modes, it was possible to calculate the $\alpha$ and $\beta$ coefficients using the first two natural frequencies.
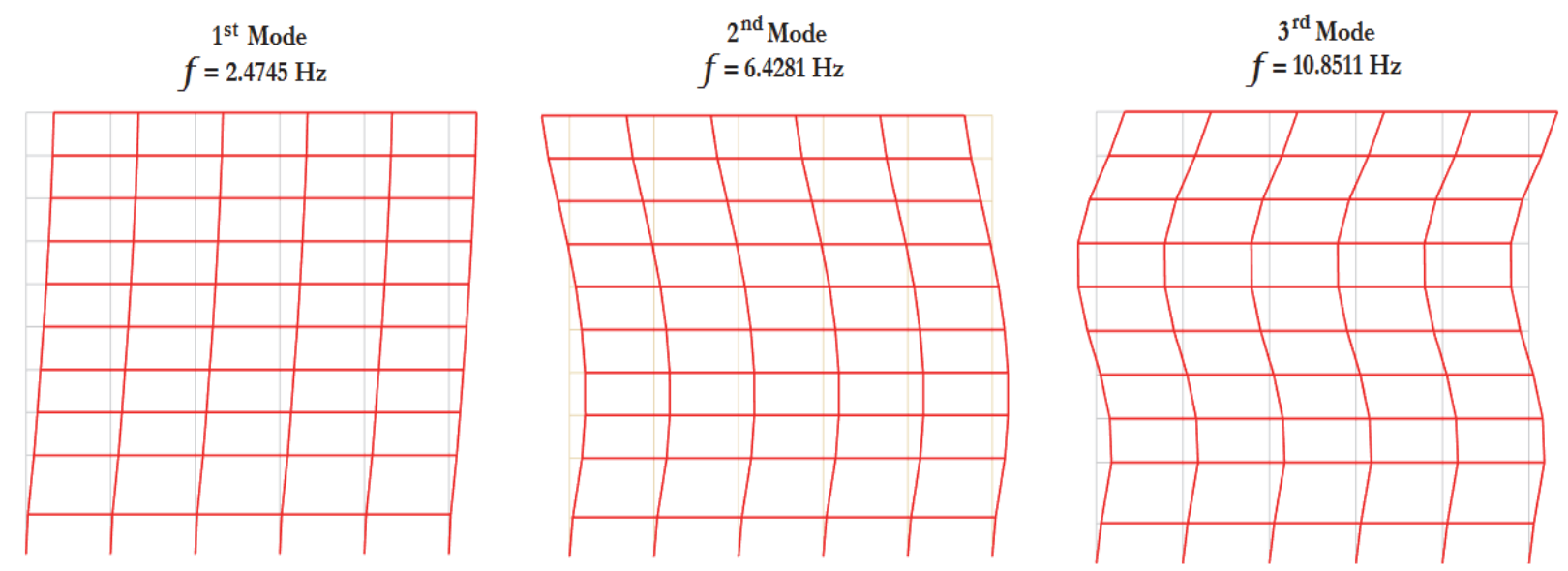

Figure 3: The first three mode shapes of the 2D steel building. 


\section{Seismic excitation}

For the seismic analyses, records of three real earthquakes (obtained from [34]), shown in Tab. 2, and a non-stationary artificial earthquake (resonant earthquake), generated by the Kanai-Tajimi Spectrum [35-36] and an envelope function adapted from [37] are used as seismic excitation.

\begin{tabular}{cccccccc}
\hline Record & Earthquake name & Country & Year & Station & M $\left(\mathrm{M}_{\mathrm{w}}\right)^{(1)}$ & $\mathrm{D}(\mathrm{km})^{(2)}$ & PGA $(\mathrm{g})^{(3)}$ \\
\hline 1 & Loma Prieta & EUA & 1989 & Santa Cruz-USCS & 7.0 & 17.5 & 0.441 \\
2 & L'Aquila & ITA & 2009 & L'Aquila-V.A-Centro Valle & 6.3 & 8.8 & 0.661 \\
3 & Canterbury & NZL & 2010 & Kaiapoi N. School & 7.0 & 5.0 & 0.343 \\
\hline
\end{tabular}

Note:

(1) M, Magnitude of the earthquake;

(2) $\mathrm{D}$, depth of the earthquake;

(3) PGA, Peak Ground Acceleration.

Table 2: Characteristics of the real earthquakes utilized.

For each real earthquake in Tab. 2, only an accelerogram of the horizontal component with the largest PGA was used. Each earthquake has a different length of time and PGA, therefore, it was decided to use only the most relevant 20s of each record and a common PGA for all, which was 0.4g. In Fig. 4 is shown the accelerogram and PSD of each record.
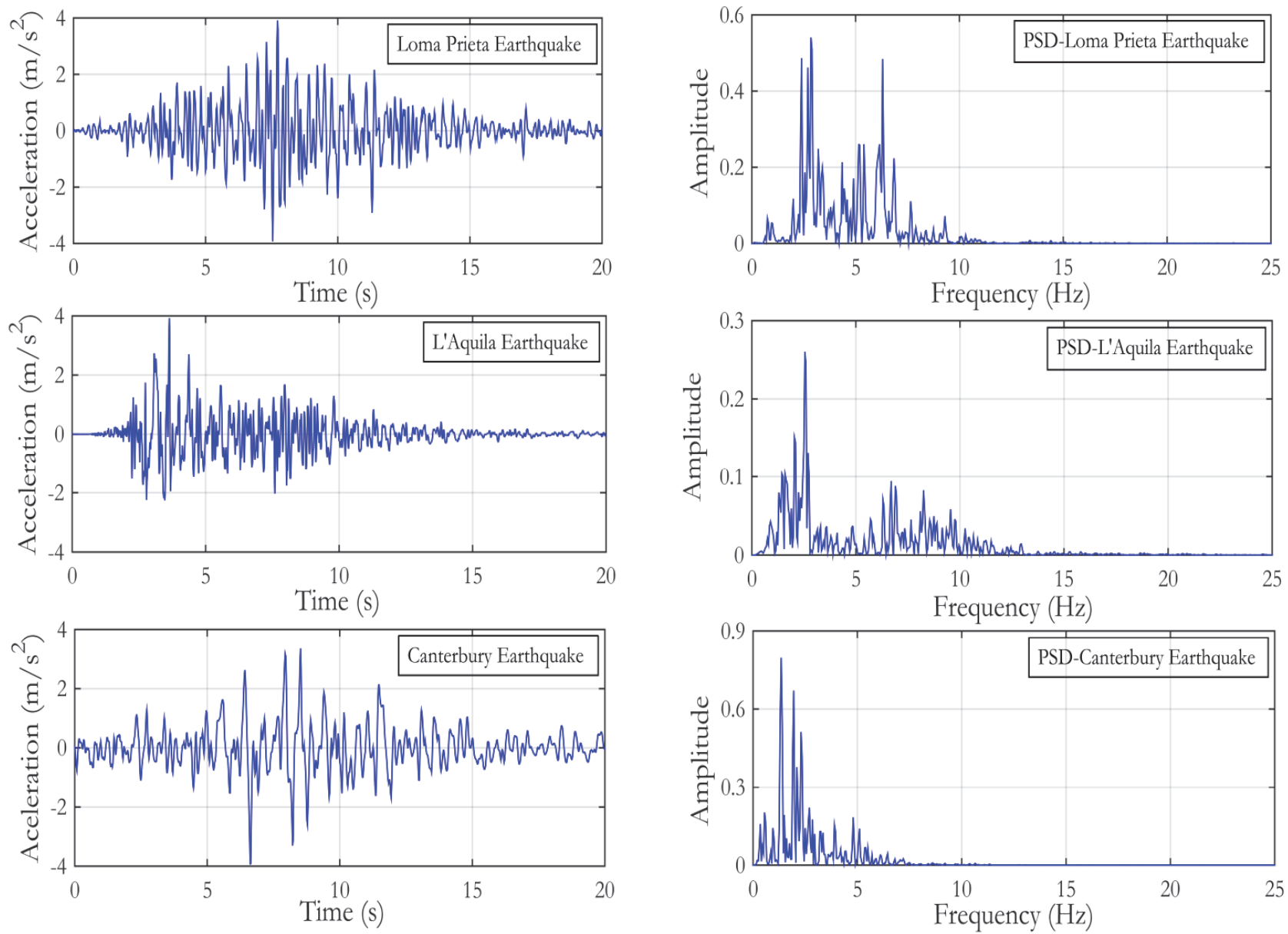

Figure 4: Accelerogram and PSD of the three real earthquakes. 
To generate a non-stationary artificial earthquake, firstly a stationary earthquake was developed using Kanai-Tajimi Spectrum, a model that presents the acceleration of the ground as a stationary random process. The equation which describes this model is given by the power spectral density function $S(\omega)$ expressed in Eq. 8 where $S_{0}$ is the spectral density constant, $\xi_{g}$ and $\omega_{g}$ are the damping and frequency of the soil, respectively. In this paper, $\xi_{g}$ and $\omega_{g}$ are equal to 0.3 and $15.5478 \mathrm{rad} / \mathrm{s}$ (first natural frequency of the building, $2.4745 \mathrm{~Hz}$ ), respectively. The spectrum obtained is shown in Fig. 5.

$$
\mathrm{S}(\omega)=\mathrm{S}_{0}\left[\frac{\omega_{\mathrm{g}}{ }^{4}+4 \omega_{\mathrm{g}}{ }^{2} \xi_{\mathrm{g}}{ }^{2} \omega^{2}}{\left(\omega^{2}-\omega_{\mathrm{g}}{ }^{2}\right)^{2}+4 \omega_{\mathrm{g}}{ }^{2} \xi_{\mathrm{g}}{ }^{2} \omega^{2}}\right] \quad \text { with } \quad \mathrm{S}_{0}=\frac{0.03 \xi_{\mathrm{g}}}{\pi \omega_{\mathrm{g}}\left(4 \xi_{\mathrm{g}}{ }^{2}+1\right)}
$$

$S(\omega)$ is a function in the frequency domain, therefore, to take it to the time domain, the Eq. 9, proposed by [38] was used. In this equation $N_{\omega}$ represents the interval number of the frequency band, $\Delta \omega$ is the frequency increment and $\phi_{j}$ is the random phase angle with values uniformly distributed from 0 to $2 \pi$.

$$
\overrightarrow{\mathrm{u}}_{\mathrm{g}}(\mathrm{t})=\sqrt{2} \sum_{\mathrm{j}=1}^{\mathrm{N}_{\omega}} \sqrt{\mathrm{S}\left(\omega_{\mathrm{j}}\right) \Delta_{\omega}} \cos \left(\omega_{\mathrm{j}} \mathrm{t}+\phi_{\mathrm{j}}\right)
$$

The signal generated in the time domain firstly has been normalized to unitary PGA and subsequently multiplied by a PGA equal to 0.4g. Finally, to simulate the transient nature of earthquakes, an envelope function proposed by [37] was adapted (Fig. 5) and used to multiplies the stationary accelerogram generated in order to obtain a new record with characteristics similar of a real earthquake, with an initial stretch of growth and a final stretch of attenuation of acceleration.
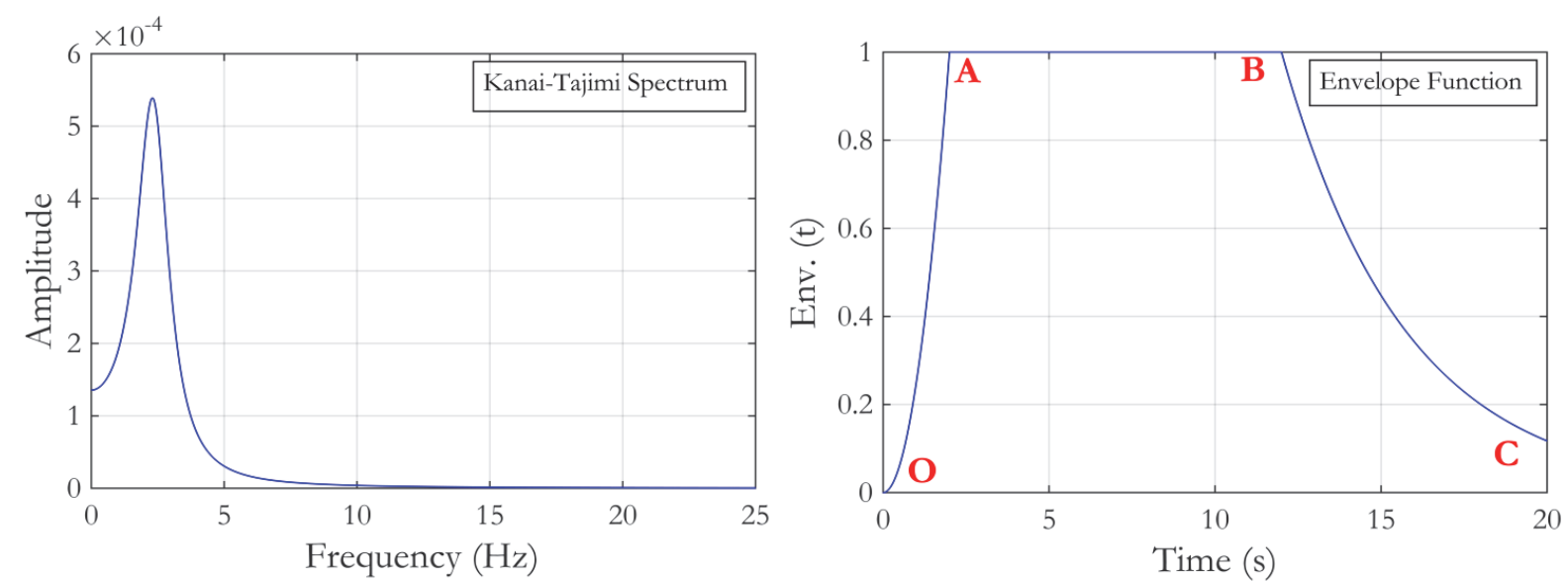

Figure 5: Kanai-Tajimi Spectrum and envelope function for Non-stationary earthquake.

The adapted envelope function consists of three intervals $\mathrm{OA}$ (increasing interval), $\mathrm{AB}$ (constant interval) and $\mathrm{BC}$ (decreasing interval), which are described by Eq. 10. Thus, a non-stationary earthquake is obtained and its accelerogram and PSD are shown in Fig. 6.

$$
\begin{aligned}
& O A: \operatorname{Env}(t)=\frac{t^{2}}{4} \\
& A B: \operatorname{Env}(t)=1 \\
& \text { BC: } \operatorname{Env}(t)=\exp [-0.268(t-12)]
\end{aligned}
$$



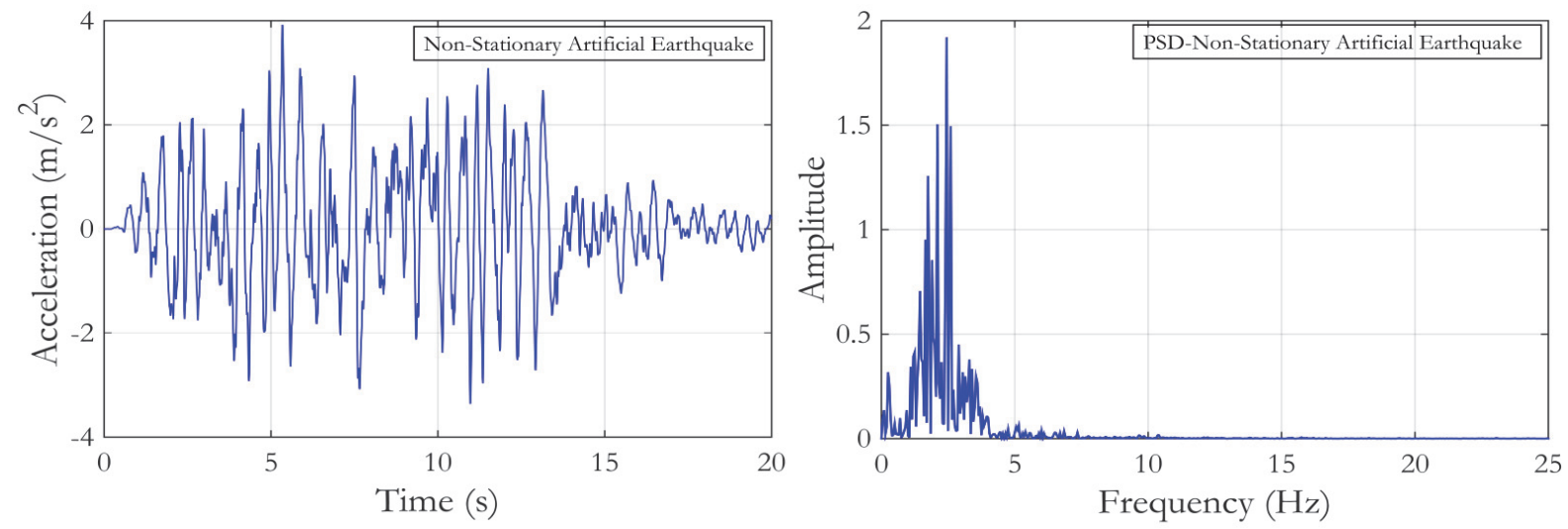

Figure 6: Non-stationary earthquake and respective PSD.

\section{The Whale Optimization Algorithm (WOA)}

An optimization problem can be solved by many ways and the metaheuristic optimization algorithms are widely used in many types of optimization engineering problems, because they: (i) do not require gradient information; (ii) do not become stuck in local minimal if correctly tuned; (iii) are based on simple concepts and are easy to implement; (iv) can be utilized to solve a mixed variables optimization problems in different fields. In this paper, the Whale Optimization Algorithm (WOA) is employed to solve three optimization problems.

WOA is a metaheuristic optimization algorithm mimicking the hunting behavior of humpback whales, proposed by [24]. In this strategy, whales search for their prey randomly and when they find it, they attack them creating bubbles and addressing them in the spiral shape. The pseudo-code of WOA is shown in Fig. 7 and according to [24] the following input parameters are necessary: $\mathrm{D}_{\mathrm{im}}$ (number of design variables); $\mathrm{f}_{\mathrm{obj}}$ (objective function); $\mathrm{N}_{\mathrm{sa}}$ (number of search agents, that is, the whale population); $\mathrm{N}_{\text {gen }}$ (maximum number of generations, that is, maximum iteration number); $\mathrm{L}_{b}$ (lower bound, where $\mathrm{L}_{b n}$ the lower bound of variable $\mathrm{n}$, for example: $\mathrm{L}_{b}=\left[\mathrm{L}_{b 1}, \mathrm{~L}_{b 2}, \ldots, \mathrm{L}_{\mathrm{bn}}\right]$ ); $\mathrm{U}_{\mathrm{b}}$ (upper bound, where $\mathrm{U}_{b n}$ the upper bound of variable $n$, for example: $\left.\mathrm{U}_{\mathrm{b}}=\left[\mathrm{U}_{\mathrm{b} 1}, \mathrm{U}_{\mathrm{b} 2}, \ldots, \mathrm{U}_{\mathrm{bn}}\right]\right)$. Fig. 7 shows the parameters which must be updated, where a is decreased from 2 to 0 in order to provide exploration and exploitation, respectively; $\mathrm{A}$ and $\mathrm{C}$, are coefficients utilized to calculate the best current solution; 1 , is a random number in $[-1,1]$; and $\mathrm{p}$, is a random number in $[0,1]$.

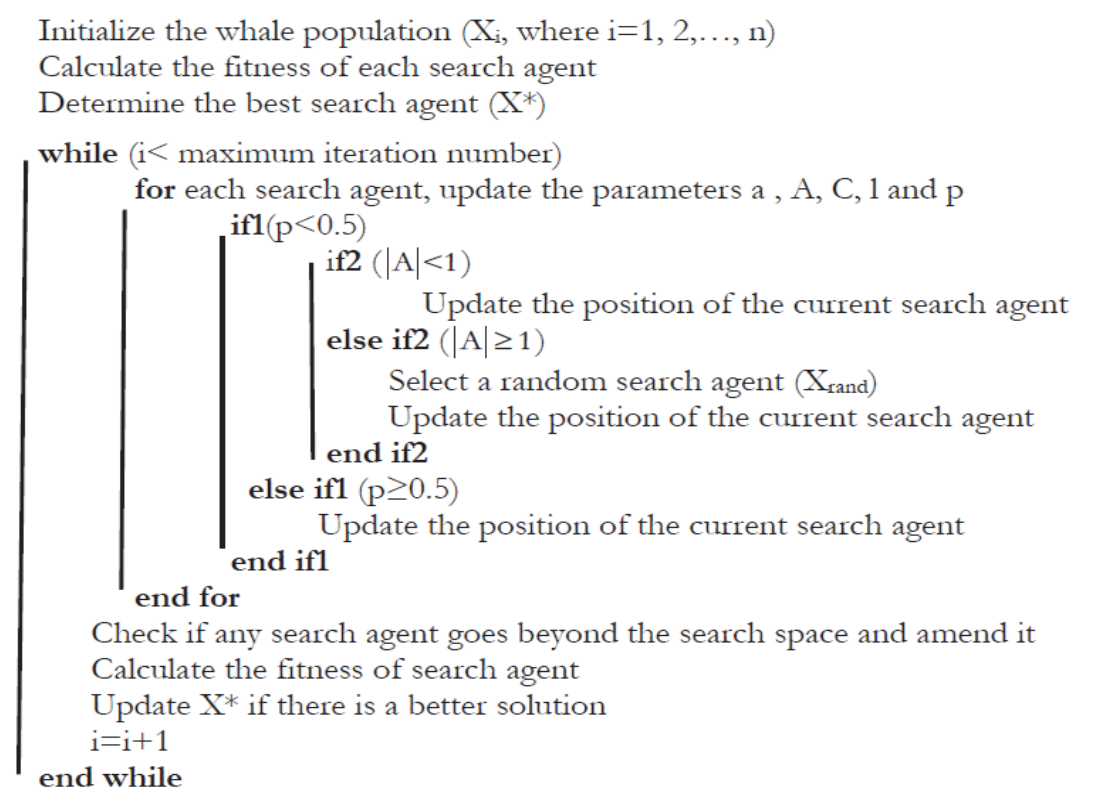

Return $\mathrm{X}^{*}$

Figure 7: Pseudo-code of the WOA [adapted from [24]]. 
As in other evolutionary approaches, WOA works with a population of potential candidates that are updated dynamically throughout the evolutionary process. Initially, a population is generated (with NP potential candidates-whales) randomly considering the search space defined by the user. Then, the operators (search for prey, encircling prey and bubble-net attacking method) are applied to generate a new population. In the new population, the best candidate found, in terms of the value of the objective function, is assumed as the optimal solution of the current generation. The procedure is repeated until a certain stopping criterion is satisfied, which is usually the maximum number of generations [24]. For more details about the mathematical model of WOA, refer [24].

\section{Formulation of the dynamic optimization problem and interstory drift limit}

The dynamic analyzes performed in this study consider a n-DOF structure, therefore, to solve the equation of motion of this system (Eq.1), it is common to use numerical integration methods, because they have two relevant characteristics. The first is to satisfy the equation to be solved in discrete time intervals separated by $\Delta t$, instead of satisfying it at all times. The second, some type of variation is allowed for displacement, velocity and acceleration, inside each time interval $\Delta$ t. In literature many numerical methods are available, and in this work, the Newmark Method is utilized. The Newmark method is an implicit method of integration and is based on the principle in which acceleration varies linearly between two instants of time. The method assumes that displacement and velocity values at time $t=0$ are known and then the initial acceleration is calculated. With this information, the solution of the differential equation of motion is determined in the interval from $\mathrm{t}=0$ to $\mathrm{t}=\mathrm{T}$, where $\mathrm{T}$ indicates the duration of excitation.

In this paper, the main aim is to reduce the maximum horizontal displacement of the top floor and interstory drift of the analyzed structure under seismic excitation using TMD with optimized parameters and positions by WOA. For this, three different scenarios are considered: single TMD installed at the top floor (Scenario 1); MTMD horizontally arranged at the top floor (Scenario 2); and MTMD vertically arranged on the structure, maximum one per floor (Scenario 3). For each scenario, the optimization problem consists in the same objective function to be minimized and the total mass for single TMD in Scenario 1 or for all devices which remain in the structure, in the Scenario 2 and Scenario 3, represents 3\% of the structural mass of the building, which corresponds to $6715 \mathrm{~kg}$. The drift criteria are considered of interstory drift according to ANSI/AISC 360-16 code of the American Institute of Steel Construction [32] as ratio 1/400 of the story height, which is, the limit of interstory drift is $h_{i} / 400$, where $b_{i}$ is the $i^{\text {th }}$ story height.

The optimization problem for Scenario 1 consists to determine the optimal parameters (spring and damping constants) for a single TMD installed on the $10^{\text {th }}$ floor which reduces the maximum horizontal displacement of the top floor and the interstory drifts. For convenience of notation, the design variables $k_{T M D}$ and $c_{T M D}$ are grouped into the vector $\vec{x}=\left[k_{T M D}, c_{T M D}\right]$. The lower bound and the upper bound value of the stiffness and damping constants of TMD are 0-8 $\mathrm{MN} / \mathrm{m}$ and $0-50 \mathrm{kNs} / \mathrm{m}$, respectively. The optimization problem in this scenario can be expressed as:

$$
\begin{aligned}
& \text { Find: } \overrightarrow{\mathrm{x}}=\left[\mathrm{k}_{\mathrm{TMD}}, \mathrm{c}_{\mathrm{TMD}}\right] \\
& \text { Minimizes: } \mathrm{f}(\overrightarrow{\mathrm{x}})=\mathrm{D}_{\text {max }, 10^{\text {th }} \text { floor }} \\
& \text { Subject to: }\left\{\begin{array}{l}
\mathrm{k}_{\mathrm{TMD}}^{\min } \leq \mathrm{k}_{\mathrm{TMD}} \leq \mathrm{k}_{\mathrm{TMD}}^{\max } \\
\mathrm{c}_{\mathrm{TMD}}^{\min } \leq \mathrm{c}_{\mathrm{TMD}} \leq \mathrm{c}_{\mathrm{TMD}}^{\max }
\end{array}\right.
\end{aligned}
$$

In Scenario 2, four TMDs, one per node, are horizontally arranged at the top floor at nodes 62, 63, 64 and 65, and each TMD has $1678.75 \mathrm{~kg}$. The optimization problem of this scenario is again to determine the optimal parameters (spring and damping constants) for each TMD in order to reduce horizontal displacement and interstory drift. The design variables vector is $\vec{x}=\left[k_{d 1}, \ldots, k_{d 4}, c_{d 1}, \ldots, c_{d 4}\right]$. The lower and upper bounds values of the stiffness and damping constants of each TMD are $0-2 \mathrm{MN} / \mathrm{m}$ and $0-12.50 \mathrm{kNs} / \mathrm{m}$, respectively. This optimization problem can be posed as:

$$
\begin{aligned}
& \text { Find: } \overrightarrow{\mathrm{x}}=\left[\mathrm{k}_{\mathrm{d} 1}, \ldots, \mathrm{k}_{\mathrm{d} 4}, \mathrm{c}_{\mathrm{d} 1}, \ldots, \mathrm{c}_{\mathrm{d} 4}\right] \\
& \text { Minimizes: } \mathrm{f}(\overrightarrow{\mathrm{x}})=\mathrm{D}_{\text {max }, 10^{\text {th }} \text { floor }} \\
& \text { Subject to: }\left\{\begin{array}{l}
k_{d}^{\text {min }} \leq \mathrm{k}_{\mathrm{d}} \leq \mathrm{k}_{\mathrm{d}}^{\max } \\
\mathrm{c}_{\mathrm{d}}^{\text {min }} \leq \mathrm{c}_{\mathrm{d}} \leq \mathrm{c}_{\mathrm{d}}^{\max }
\end{array}\right.
\end{aligned}
$$


For Scenario 3, MTMD are vertically arranged on the structure, maximum one per floor, and the optimization algorithm indicates the best position and optimal parameters of each TMD, and, indirectly the number of dampers. The design variables are the spring and damping constants and the position of each TMD in the structure. The position for each device is grouped into the vector of damper positions $(\vec{p})$ which contains 0 and 1 , where 1 indicates that there is a TMD in this position. The number of available positions $\left(n_{p}\right)$ is a constraint and its maximum value is 10 (one TMD in each story). Thus, the maximum number of ones in $\vec{p}$ indicates another constraint, the maximum number of TMD $\left(n_{T M D}\right)$. The mass of all devices, as mentioned earlier, was fixed as 3\% of the structural mass of the building and the mass of each TMD $\left(m_{d}\right)$ is the same and it is defined by $n_{\text {TMD }}$. The possible positions of MTMD are given to the nodes 9, 15, 21, 27, 33, $39,45,51,57$ and 63. The lower and upper bounds values of the stiffness and damping constants of each TMD are $0-2$ $\mathrm{MN} / \mathrm{m}$ and 0-12.50 kNs/m, respectively. Finally, the optimization problem for Scenario 3 can be expressed as:

Find: $\overrightarrow{\mathrm{x}}=\left[\overrightarrow{\mathrm{p}}, \mathrm{k}_{\mathrm{d} 1}, \ldots, \mathrm{k}_{\mathrm{dn}_{\mathrm{TMI}}}, \mathrm{c}_{\mathrm{d} 1}, \ldots, \mathrm{c}_{\mathrm{dn}_{\mathrm{TMI}}}\right]$

Minimizes: $\mathrm{f}(\overrightarrow{\mathrm{x}})=\mathrm{D}_{\text {max }, 10^{\text {th }} \text { floor }}$

$$
\text { Subject to: }\left\{\begin{array}{l}
\mathrm{k}_{\mathrm{d}}^{\min } \leq \mathrm{k}_{\mathrm{d}} \leq \mathrm{k}_{\mathrm{d}}^{\max } \\
\mathrm{c}_{\mathrm{d}}^{\min } \leq \mathrm{c}_{\mathrm{d}} \leq \mathrm{c}_{\mathrm{d}}^{\max } \\
\text { number of available positions }=\mathrm{n}_{\mathrm{p}} \\
\text { maximum number of dampers }=\mathrm{n}_{\mathrm{TMD}} \\
\sum \mathrm{m}_{\mathrm{d}}=0.03 \mathrm{M}_{\text {structure }}
\end{array}\right.
$$

\section{RESULTS AND DISCUSSIONS}

T

he building analyzed in this paper, as mentioned earlier and shown in Fig. 2, has 10 floors where the first and second floors have $3.65 \mathrm{~m}$ and $5.49 \mathrm{~m}$ of height, respectively, and for the third to tenth floors, each one has 3.96 $\mathrm{m}$ of height, totalizing $40.82 \mathrm{~m}$ of height. According to ANSI/AISC 360-16 code of the American Institute of Steel Construction [32], the interstory drift limits for each floor can be given as ratio $b_{i} / 400$, where $h_{i}$ is the $i^{i t}$ story height. Thus, the interstory drift limits to the $1^{\text {st }}$ floor is $0.0091 \mathrm{~m}$, to the $2^{\text {nd }}$ floor is $0.0137 \mathrm{~m}$ and for the $3^{\text {rd }}$ to $10^{\text {th }}$ floors is $0.0099 \mathrm{~m}$. In Tab. 3 the value of the maximum displacement to each story $\left(D_{\max }\right)$, the interstory drift (ISD) and the interstory drift limits $\left(I S D_{\text {limit }}\right)$ of the uncontrolled structure under the four earthquake records are reported.

\begin{tabular}{|c|c|c|c|c|c|c|c|c|c|}
\hline \multicolumn{10}{|c|}{ Response of uncontrolled structure } \\
\hline \multirow{2}{*}{$\begin{array}{l}\text { Story } \\
\text { number }\end{array}$} & \multirow{2}{*}{$\mathrm{ISD}_{\text {limit }}(\mathrm{m})$} & \multicolumn{2}{|c|}{ Loma Prieta Earthquake } & \multicolumn{2}{|c|}{ L'Aquila Earthquake } & \multicolumn{2}{|c|}{ Canterbury Earthquake } & \multicolumn{2}{|c|}{$\begin{array}{c}\text { Non-Stationary } \\
\text { Artificial Earthquake }\end{array}$} \\
\hline & & $\mathrm{D}_{\max }(\mathrm{m})$ & ISD (m) & $\mathrm{D}_{\max }(\mathrm{m})$ & ISD (m) & $\mathrm{D}_{\max }(\mathrm{m})$ & ISD (m) & $\mathrm{D}_{\max }(\mathrm{m})$ & ISD (m) \\
\hline 1 & 0.0091 & 0.0067 & 0.0067 & 0.0064 & 0.0064 & 0.0072 & 0.0072 & 0.0117 & 0.0117 \\
\hline 2 & 0.0137 & 0.0281 & 0.0214 & 0.0270 & 0.0206 & 0.0300 & 0.0228 & 0.0497 & 0.0380 \\
\hline 3 & 0.0099 & 0.0396 & 0.0116 & 0.0384 & 0.0114 & 0.0426 & 0.0127 & 0.0713 & 0.0216 \\
\hline 4 & 0.0099 & 0.0494 & 0.0098 & 0.0484 & 0.0102 & 0.0539 & 0.0112 & 0.0910 & 0.0197 \\
\hline 5 & 0.0099 & 0.0584 & 0.0108 & 0.0582 & 0.0105 & 0.0648 & 0.0110 & 0.1109 & 0.0199 \\
\hline 6 & 0.0099 & 0.0652 & 0.0100 & 0.0662 & 0.0092 & 0.0739 & 0.0094 & 0.1278 & 0.0169 \\
\hline 7 & 0.0099 & 0.0712 & 0.0100 & 0.0732 & 0.0086 & 0.0818 & 0.0090 & 0.1432 & 0.0153 \\
\hline 8 & 0.0099 & 0.0805 & 0.0093 & 0.0792 & 0.0076 & 0.0883 & 0.0081 & 0.1562 & 0.0130 \\
\hline 9 & 0.0099 & 0.0890 & 0.0085 & 0.0853 & 0.0067 & 0.0938 & 0.0072 & 0.1674 & 0.0112 \\
\hline 10 & 0.0099 & 0.0945 & 0.0054 & 0.0892 & 0.0042 & 0.0972 & 0.0046 & 0.1743 & 0.0069 \\
\hline
\end{tabular}

Table 3: Maximum displacement and interstory drift of uncontrolled structure under the four earthquakes records. 
Looking Tab. 3 it is important to note to the Loma Prieta Earthquake the ISD of story numbers 2, 3, 5, 6 and 7 exceed $I S D_{\text {limit. }}$ To the L'Aquila Earthquake and Canterbury Earthquake the story numbers 2, 3, 4, and 5 exceed ISD $D_{\text {limit. }}$ And to the Non-Stationary Artificial Earthquake, the non-stationary artificial earthquake which could generate resonance of structure, only the story number 10 did not exceed $I S D_{\text {limit. }}$ Therefore, this building requires a vibration control system in order to reduce the interstory drift to the imposed limits. Thus, in Scenario 1 a vibration control using a single TMD of mass $m_{d}=6715 \mathrm{~kg}$ installed at the top floor of the building, at node 63, was proposed. The parameters ( $k_{T M D}$ and $\left.C_{T M D}\right)$ were optimized through the optimization problem shown in Eq. 11. In the WOA the number of search agents and interactions were defined in 50 and 100, respectively. The convergence curve of this problem is presented in Fig. 8 which resulted in optimal values for spring and damping constants corresponding to $k_{T M D}=1513880 \mathrm{~N} / \mathrm{m}$ and $c_{T M D}=32878$ N.s $/ \mathrm{m}$ and the TMD frequency of $f_{T M D}=2.3897 \mathrm{~Hz}$. The results obtained for this scenario are reported in Tab. 4 and the percentage of reduction of $D_{\max }$ and ISD regarding the uncontrolled structure is shown in Tab. 5.

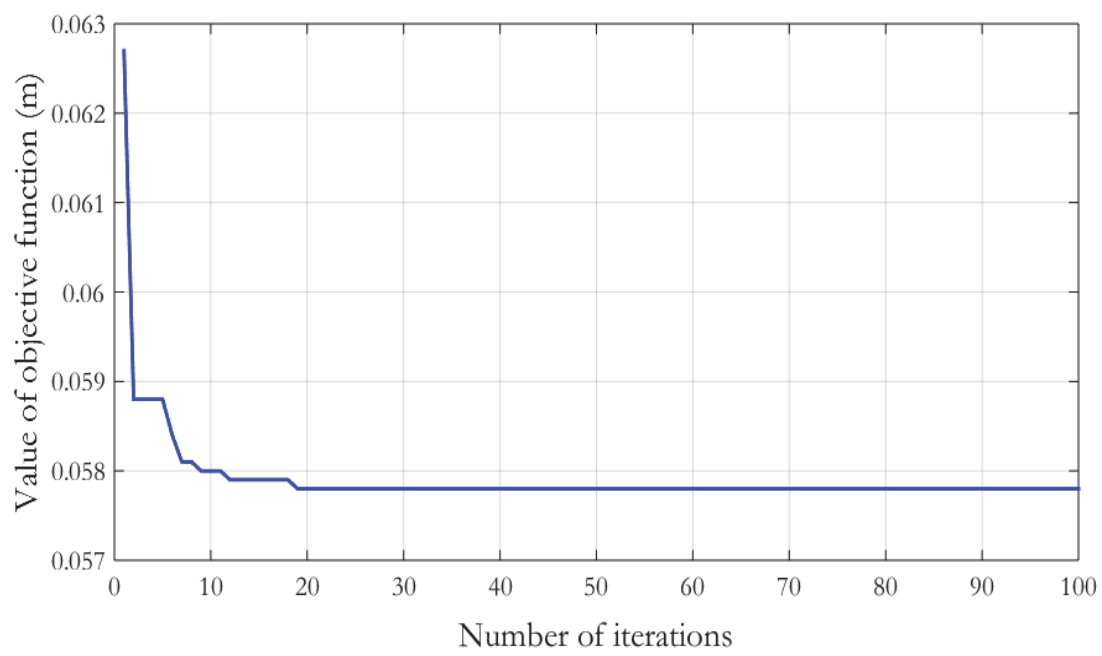

Figure 8: Convergence curve of Scenario 1.

\begin{tabular}{|c|c|c|c|c|c|c|c|c|c|}
\hline \multirow{3}{*}{$\begin{array}{l}\text { Story } \\
\text { number }\end{array}$} & \multirow{3}{*}{$\operatorname{ISD}_{\text {limit }}(\mathrm{m})$} & \multicolumn{6}{|c|}{ Scenario 1- Response to single TMD at the top floor } & \multirow{2}{*}{\multicolumn{2}{|c|}{$\begin{array}{c}\text { Non-Stationary } \\
\text { Artificial Earthquake }\end{array}$}} \\
\hline & & \multicolumn{2}{|c|}{ Loma Prieta Earthquake } & \multicolumn{2}{|c|}{ L'Aquila Earthquake } & \multicolumn{2}{|c|}{ Canterbury Earthquake } & & \\
\hline & & $\mathrm{D}_{\max }(\mathrm{m})$ & $\operatorname{ISD}(\mathrm{m})$ & $\mathrm{D}_{\max }(\mathrm{m})$ & $\operatorname{ISD}(\mathrm{m})$ & $\mathrm{D}_{\max }(\mathrm{m})$ & $\operatorname{ISD}(\mathrm{m})$ & $\mathrm{D}_{\max }(\mathrm{m})$ & $\operatorname{ISD}(\mathrm{m})$ \\
\hline 1 & 0.0091 & 0.0030 & 0.0030 & 0.0025 & 0.0025 & 0.0036 & 0.0036 & 0.0039 & 0.0039 \\
\hline 2 & 0.0137 & 0.0126 & 0.0096 & 0.0111 & 0.0086 & 0.0152 & 0.0117 & 0.0166 & 0.0127 \\
\hline 3 & 0.0099 & 0.0177 & 0.0051 & 0.0161 & 0.0050 & 0.0219 & 0.0067 & 0.0238 & 0.0072 \\
\hline 4 & 0.0099 & 0.0218 & 0.0045 & 0.0207 & 0.0045 & 0.0281 & 0.0062 & 0.0303 & 0.0065 \\
\hline 5 & 0.0099 & 0.0253 & 0.0052 & 0.0250 & 0.0044 & 0.0344 & 0.0063 & 0.0369 & 0.0066 \\
\hline 6 & 0.0099 & 0.0278 & 0.0052 & 0.0283 & 0.0035 & 0.0397 & 0.0055 & 0.0423 & 0.0058 \\
\hline 7 & 0.0099 & 0.0332 & 0.0055 & 0.0310 & 0.0035 & 0.0446 & 0.0053 & 0.0471 & 0.0056 \\
\hline 8 & 0.0099 & 0.0385 & 0.0053 & 0.0331 & 0.0033 & 0.0489 & 0.0048 & 0.0512 & 0.0052 \\
\hline 9 & 0.0099 & 0.0436 & 0.0051 & 0.0350 & 0.0036 & 0.0533 & 0.0047 & 0.0549 & 0.0052 \\
\hline 10 & 0.0099 & 0.0470 & 0.0035 & 0.0366 & 0.0029 & 0.0565 & 0.0035 & 0.0578 & 0.0043 \\
\hline TMD & - & 0.0903 & - & 0.1031 & - & 0.1300 & - & 0.1875 & - \\
\hline
\end{tabular}

Table 4: Maximum displacements and interstory drifts of the structure under the four earthquakes records to Scenario 1. 


\begin{tabular}{|c|c|c|c|c|c|c|c|c|}
\hline \multirow{3}{*}{ Story number } & \multicolumn{6}{|c|}{ Scenario 1- Percentage of response reduction } & \multirow{2}{*}{\multicolumn{2}{|c|}{$\begin{array}{c}\text { Non-Stationary Artificial } \\
\text { Earthquake }\end{array}$}} \\
\hline & \multicolumn{2}{|c|}{ Loma Prieta Earthquake } & \multicolumn{2}{|c|}{ L'Aquila Earthquake } & \multicolumn{2}{|c|}{ Canterbury Earthquake } & & \\
\hline & $\mathrm{D}_{\max }(\%)$ & ISD $(\%)$ & $\mathrm{D}_{\max }(\%)$ & ISD $(\%)$ & $\mathrm{D}_{\max }(\%)$ & ISD $(\%)$ & $\mathrm{D}_{\max }(\%)$ & ISD $(\%)$ \\
\hline 1 & 55.22 & 55.22 & 60.94 & 60.94 & 50.00 & 50.00 & 66.67 & 66.67 \\
\hline 2 & 55.16 & 55.14 & 58.89 & 58.25 & 49.33 & 48.68 & 66.60 & 66.58 \\
\hline 3 & 55.30 & 56.03 & 58.07 & 56.14 & 48.59 & 47.24 & 66.62 & 66.67 \\
\hline 4 & 55.87 & 54.08 & 57.23 & 55.88 & 47.87 & 44.64 & 66.70 & 67.01 \\
\hline 5 & 56.68 & 51.85 & 57.04 & 58.10 & 46.91 & 42.73 & 66.73 & 66.83 \\
\hline 6 & 57.36 & 48.00 & 57.25 & 61.96 & 46.28 & 41.49 & 66.90 & 65.68 \\
\hline 7 & 53.37 & 45.00 & 57.65 & 59.30 & 45.48 & 41.11 & 67.11 & 63.40 \\
\hline 8 & 52.17 & 43.01 & 58.21 & 56.58 & 44.62 & 40.74 & 67.22 & 60.00 \\
\hline 9 & 51.01 & 40.00 & 58.97 & 46.27 & 43.18 & 34.72 & 67.20 & 53.57 \\
\hline 10 & 50.26 & 35.19 & 58.97 & 30.95 & 41.87 & 23.91 & 66.84 & 37.68 \\
\hline
\end{tabular}

Table 5: Percentage of reduction of the maximum displacements and interstory drifts of the structure under the four earthquakes records regarding uncontrolled structure to Scenario 1.

Analyzing Tabs. 4 and 5, it is possible to note that the structure equipped with a single TMD at the top floor had a significant reduction of maximum displacements per floor and interstory drift when compared to the uncontrolled structure. This scenario presented the lowest top displacement to the Loma Prieta Earthquake $(0.047 \mathrm{~m})$, when compared to use of the same record in the other scenarios. To the four earthquakes records, the reduced interstory drifts are below the allowed limit to each floor. In this scenario, to the $2^{\text {nd }}$ floor (which presented the highest interstory drift value for the uncontrolled structure), the lowest value was obtained for L'Aquila Earthquake $(0.0086 \mathrm{~m})$ which represents $58.25 \%$ of reduction regarding uncontrolled structure. However, for the Non-Stationary Artificial Earthquake (resonant earthquake) even with a significant reduction $(66.58 \%)$, the new value $(0.0127 \mathrm{~m})$ is still close to $\mathrm{ISD}_{\text {limit }}=0.0137 \mathrm{~m}$. This is related to the total response of the structure and also, to the floor height. Therefore, a new control scenario was proposed.

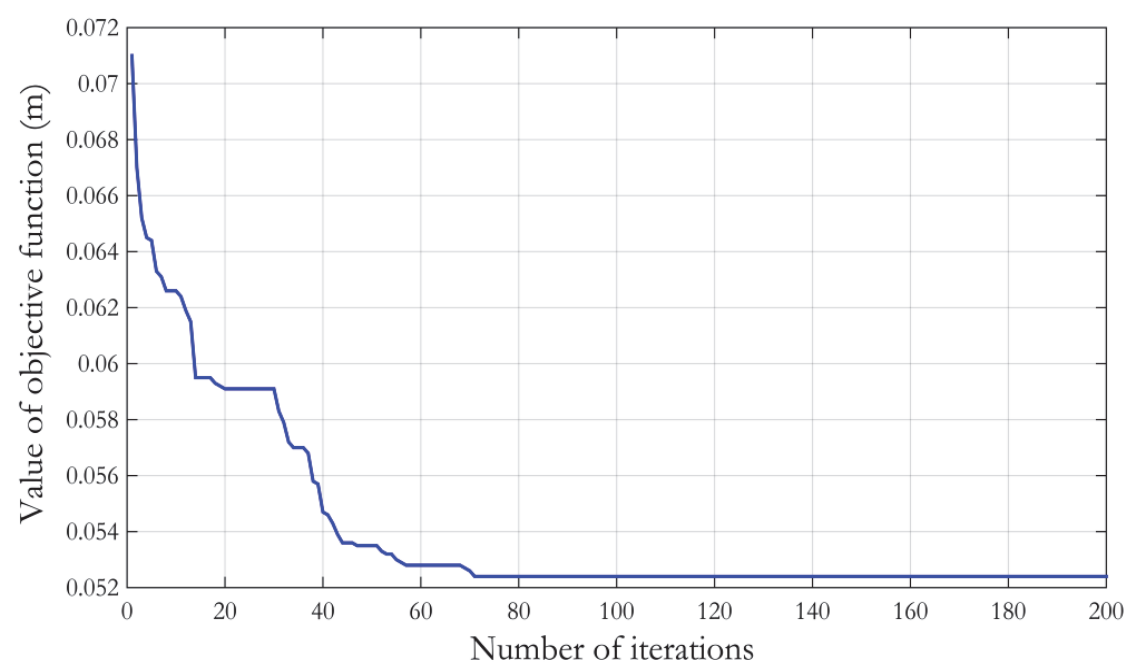

Figure 9: Convergence curve of Scenario 2. 
Scenario 2 proposes a vibration control using four TMDs horizontally arranged at the top floor at nodes 62, 63, 64 and 65. The optimization problem of this scenario is represented by Eq. 12 and consists to determine the optimal parameters of spring and damping constants for each TMD. The number of search agents and interactions was defined as 50 and 200 , respectively. The convergence curve for this scenario is presented in Fig. 9 and the optimal parameters are presented in Tab. 6.

\begin{tabular}{cccccc}
\hline TMD number & Location node & $\mathrm{m}_{\mathrm{d}}(\mathrm{kg})$ & $\mathrm{k}_{\mathrm{d}}(\mathrm{N} / \mathrm{m})$ & $\mathrm{c}_{\mathrm{d}}(\mathrm{N} . \mathrm{s} / \mathrm{m})$ & $f_{\mathrm{TMD}}(\mathrm{Hz})$ \\
\hline 1 & 62 & 1678.75 & 312346 & 8204 & 2.1709 \\
2 & 63 & 1678.75 & 416296 & 1220 & 2.5063 \\
3 & 64 & 1678.75 & 258753 & 4654 & 1.9759 \\
4 & 65 & 1678.75 & 389261 & 8755 & 2.4235 \\
\hline
\end{tabular}

Table 6: Optimal parameters of MTMD of Scenario 2.

The frequencies of the four TMDs are around the first natural frequency of building indicating that the devices are being tuned near to the $1^{\text {st }}$ mode. The maximum displacements per floor and interstory drift obtained to this scenario are reported in Tab. 7 and the percentage of reduction of $D_{\max }$ to each story and ISD regarding the uncontrolled structure is shown in Tab. 8.

\begin{tabular}{|c|c|c|c|c|c|c|c|c|c|}
\hline \multirow{3}{*}{$\begin{array}{c}\text { Story } \\
\text { number }\end{array}$} & \multirow{3}{*}{$\operatorname{ISD}_{\text {limit }}(\mathrm{m})$} & \multicolumn{6}{|c|}{ Scenario 2- Response to 4 TMDs horizontally arranged at the top floor } & \multirow{2}{*}{\multicolumn{2}{|c|}{$\begin{array}{l}\text { Non-Stationary } \\
\text { Artificial Earthquake }\end{array}$}} \\
\hline & & \multicolumn{2}{|c|}{ Loma Prieta Earthquake } & \multicolumn{2}{|c|}{ L'Aquila Earthquake } & \multicolumn{2}{|c|}{ Canterbury Earthquake } & & \\
\hline & & $\mathrm{D}_{\max }(\mathrm{m})$ & $\operatorname{ISD}(\mathrm{m})$ & $\mathrm{D}_{\max }(\mathrm{m})$ & $\operatorname{ISD}(\mathrm{m})$ & $\mathrm{D}_{\max }(\mathrm{m})$ & $\operatorname{ISD}(\mathrm{m})$ & $\mathrm{D}_{\max }(\mathrm{m})$ & $\operatorname{ISD}(\mathrm{m})$ \\
\hline 1 & 0.0091 & 0.0033 & 0.0033 & 0.0024 & 0.0024 & 0.0037 & 0.0037 & 0.0038 & 0.0038 \\
\hline 2 & 0.0137 & 0.0141 & 0.0108 & 0.0107 & 0.0082 & 0.0157 & 0.0121 & 0.0161 & 0.0123 \\
\hline 3 & 0.0099 & 0.0199 & 0.0058 & 0.0155 & 0.0048 & 0.0226 & 0.0069 & 0.0230 & 0.0070 \\
\hline 4 & 0.0099 & 0.0245 & 0.0052 & 0.0198 & 0.0043 & 0.0290 & 0.0063 & 0.0293 & 0.0063 \\
\hline 5 & 0.0099 & 0.0286 & 0.0060 & 0.0239 & 0.0041 & 0.0354 & 0.0064 & 0.0355 & 0.0062 \\
\hline 6 & 0.0099 & 0.0320 & 0.0058 & 0.0270 & 0.0032 & 0.0409 & 0.0056 & 0.0405 & 0.0050 \\
\hline 7 & 0.0099 & 0.0380 & 0.0060 & 0.0295 & 0.0031 & 0.0459 & 0.0052 & 0.0448 & 0.0049 \\
\hline 8 & 0.0099 & 0.0436 & 0.0057 & 0.0314 & 0.0032 & 0.0502 & 0.0047 & 0.0481 & 0.0050 \\
\hline 9 & 0.0099 & 0.0488 & 0.0052 & 0.0331 & 0.0036 & 0.0540 & 0.0045 & 0.0508 & 0.0053 \\
\hline 10 & 0.0099 & 0.0521 & 0.0035 & 0.0346 & 0.0029 & 0.0567 & 0.0033 & 0.0524 & 0.0044 \\
\hline
\end{tabular}

Table 7: Maximum displacements and interstory drifts of structure under the four earthquakes records to Scenario 2.

Looking Tab. 7, it is noted that in this scenario the structure had a significant reduction of maximum displacements per floor and the interstory drift regarding the uncontrolled structure. The top displacement for this scenario, regarding the L'Aquila Earthquake $(0.0346 \mathrm{~m})$ and resonant earthquake $(0.0524)$ are the lowest of the three scenarios. The reduced interstory drift, to the four earthquakes, is below the allowed limit to each floor. The best reduction of interstory drift to the $2^{\text {nd }}$ floor (the critical floor), considering the three scenarios, was obtained for the L'Aquila Earthquake (0.0082 m) which corresponds to $60.19 \%$ of reduction according to Tab. 8 . To the resonant earthquake, the reduced interstory drift of the $2^{\text {nd }}$ floor corresponds to $0.0123 \mathrm{~m}$, which is $67.63 \%$ of reduction, and it was the lowest value, for this seismic 
excitation, in the three scenarios. However, it is still close to the limit of $0.0137 \mathrm{~m}$, therefore the Scenario 3 was proposed where MTMD are vertically arranged on the structure, maximum one per floor.

The optimization problem of this scenario is presented in Eq. 13 and consists to determine the best position and optimal parameters of each TMD. In WOA, the number of search agents and interactions was defined as 50 and 300 , respectively. The convergence curve for this scenario is presented in Fig. 10.

\begin{tabular}{|c|c|c|c|c|c|c|c|c|}
\hline \multirow{3}{*}{ Story number } & \multicolumn{6}{|c|}{ Scenario 2- Percentage of response reduction } & \multirow{2}{*}{\multicolumn{2}{|c|}{$\begin{array}{c}\text { Non-Stationary Artificia } \\
\text { Earthquake }\end{array}$}} \\
\hline & \multicolumn{2}{|c|}{ Loma Prieta Earthquake } & \multicolumn{2}{|c|}{ L'Aquila Earthquake } & \multicolumn{2}{|c|}{ Canterbury Earthquake } & & \\
\hline & $\mathrm{D}_{\max }(\%)$ & ISD $(\%)$ & $D_{\max }(\%)$ & ISD $(\%)$ & $\mathrm{D}_{\max }(\%)$ & ISD (\%) & $\mathrm{D}_{\max }(\%)$ & ISD (\%) \\
\hline 1 & 50.75 & 50.75 & 62.50 & 62.50 & 48.61 & 48.61 & 67.52 & 67.52 \\
\hline 2 & 49.82 & 49.53 & 60.37 & 60.19 & 47.67 & 46.93 & 67.61 & 67.63 \\
\hline 3 & 49.75 & 50.00 & 59.64 & 57.89 & 46.95 & 45.67 & 67.74 & 67.59 \\
\hline 4 & 50.40 & 46.94 & 59.09 & 57.84 & 46.20 & 43.75 & 67.80 & 68.02 \\
\hline 5 & 51.03 & 44.44 & 58.93 & 60.95 & 45.37 & 41.82 & 67.99 & 68.84 \\
\hline 6 & 50.92 & 42.00 & 59.21 & 65.22 & 44.65 & 40.43 & 68.31 & 70.41 \\
\hline 7 & 46.63 & 40.00 & 59.70 & 63.95 & 43.89 & 42.22 & 68.72 & 67.97 \\
\hline 8 & 45.84 & 38.71 & 60.35 & 57.89 & 43.15 & 41.98 & 69.21 & 61.54 \\
\hline 9 & 45.17 & 38.82 & 61.20 & 46.27 & 42.43 & 37.50 & 69.65 & 52.68 \\
\hline 10 & 44.87 & 35.19 & 61.21 & 30.95 & 41.67 & 28.26 & 69.94 & 36.23 \\
\hline
\end{tabular}

Table 8: Percentage of reduction of the maximum displacements and interstory drifts of the structure under the four earthquakes records regarding uncontrolled structure to Scenario 2.

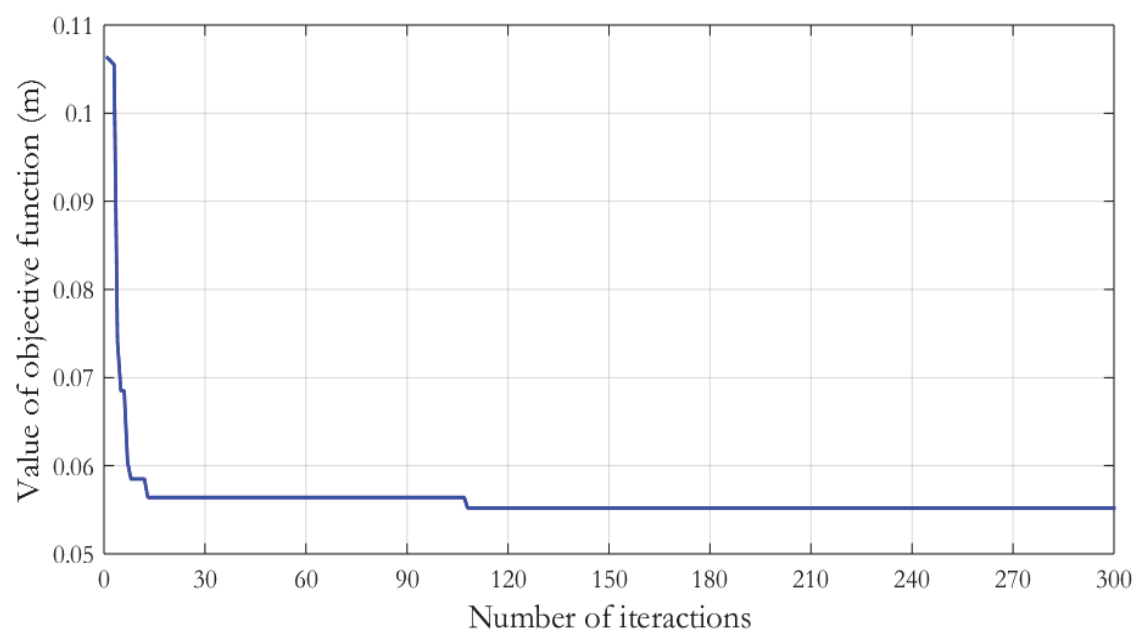

Figure 10: Convergence curve of Scenario 3.

The optimization procedure resulted in four devices to be installed one per floor at the, $3^{\text {rd }}, 7^{\text {th }}, 8^{\text {th }}$ and $9^{\text {th }}$ floor, which is, the maximum number of TMD $n_{T M D}=4$. The mass of each damper was expressed according to the $n_{T M D}$. In Tab. 9 the best position vector and optimal parameters are presented where it can be seen that the frequencies of the four devices are around the first natural frequency of building and the TMD number 8 presents the nearest value. For this scenario, the maximum displacements per floor and interstory drift are reported in Tab. 10 and the percentage of reduction of $D_{\max }$ to each story and ISD regarding the uncontrolled structure in Tab. 11. 


\begin{tabular}{cccccccc}
\hline Story number & TMD number & $\vec{p}$ & Location node & $\mathrm{m}_{\mathrm{d}}(\mathrm{kg})$ & $\mathrm{k}_{\mathrm{d}}(\mathrm{N} / \mathrm{m})$ & $\mathrm{c}_{\mathrm{d}}(\mathrm{N} . \mathrm{s} / \mathrm{m})$ & $f_{\mathrm{TMD}}(\mathrm{Hz})$ \\
1 & 1 & 0 & 9 & - & - & - & - \\
2 & 2 & 0 & 15 & - & - & - & - \\
3 & 3 & 1 & 21 & 1678.75 & 623047 & 3989 & 3.0661 \\
4 & 4 & 0 & 27 & - & - & - & - \\
5 & 5 & 0 & 33 & - & - & - \\
6 & 6 & 0 & 39 & - & - & - & 2324 \\
7 & 7 & 1 & 45 & 1678.75 & 494359 & 2.7312 \\
8 & 8 & 1 & 51 & 1678.75 & 408683 & 1235 & 2.4832 \\
9 & 9 & 1 & 57 & 1678.75 & 304062 & 2580 & 2.1419 \\
\hline
\end{tabular}

Table 9: Best position and optimal parameters of MTMD of Scenario 3.

\begin{tabular}{|c|c|c|c|c|c|c|c|c|c|}
\hline \multirow{3}{*}{$\begin{array}{l}\text { Story } \\
\text { number }\end{array}$} & \multicolumn{9}{|c|}{ Scenario 3- Response to 4 TMDs vertically arranged along the structure } \\
\hline & \multirow{2}{*}{$\mathrm{ISD}_{\text {limit }}(\mathrm{m})$} & \multicolumn{2}{|c|}{ Loma Prieta Earthquake } & \multicolumn{2}{|c|}{ L'Aquila Earthquake } & \multicolumn{2}{|c|}{ Canterbury Earthquake } & \multicolumn{2}{|c|}{$\begin{array}{l}\text { Non-Stationary } \\
\text { Artificial Earthquake }\end{array}$} \\
\hline & & $\mathrm{D}_{\max }(\mathrm{m})$ & $\operatorname{ISD}(\mathrm{m})$ & $\mathrm{D}_{\max }(\mathrm{m})$ & $\operatorname{ISD}(\mathrm{m})$ & $\mathrm{D}_{\max }(\mathrm{m})$ & ISD (m) & $\mathrm{D}_{\max }(\mathrm{m})$ & $\operatorname{ISD}(\mathrm{m})$ \\
\hline 1 & 0.0091 & 0.0033 & 0.0033 & 0.0026 & 0.0026 & 0.0038 & 0.0038 & 0.0041 & 0.0041 \\
\hline 2 & 0.0137 & 0.0142 & 0.0108 & 0.0112 & 0.0086 & 0.0160 & 0.0123 & 0.0170 & 0.0129 \\
\hline 3 & 0.0099 & 0.0200 & 0.0059 & 0.0163 & 0.0051 & 0.0231 & 0.0070 & 0.0242 & 0.0072 \\
\hline 4 & 0.0099 & 0.0248 & 0.0055 & 0.0209 & 0.0046 & 0.0295 & 0.0064 & 0.0305 & 0.0064 \\
\hline 5 & 0.0099 & 0.0291 & 0.0063 & 0.0253 & 0.0044 & 0.0361 & 0.0066 & 0.0368 & 0.0063 \\
\hline 6 & 0.0099 & 0.0344 & 0.0060 & 0.0286 & 0.0040 & 0.0417 & 0.0057 & 0.0420 & 0.0055 \\
\hline 7 & 0.0099 & 0.0407 & 0.0063 & 0.0313 & 0.0040 & 0.0469 & 0.0054 & 0.0466 & 0.0052 \\
\hline 8 & 0.0099 & 0.0466 & 0.0059 & 0.0334 & 0.0036 & 0.0512 & 0.0046 & 0.0502 & 0.0045 \\
\hline 9 & 0.0099 & 0.0520 & 0.0054 & 0.0363 & 0.0032 & 0.0548 & 0.0038 & 0.0532 & 0.0039 \\
\hline 10 & 0.0099 & 0.0555 & 0.0035 & 0.0381 & 0.0021 & 0.0570 & 0.0023 & 0.0552 & 0.0025 \\
\hline
\end{tabular}

Table 10: Maximum displacements and interstory drifts of the structure under the four earthquakes records to Scenario 3.

Tab. 10 shows that to the four earthquakes records the interstory drift are below the allowed limit to each floor and represents an important reduction considering the uncontrolled structure. Comparing this scenario to Scenarios 1 and 2 , it was observed that it does not present the lowest reductions of top displacement and neither the lowest interstory drift for the $2^{\text {nd }}$ floor. However, comparing only the results of this scenario, to the $2^{\text {nd }}$ floor the lowest value was obtained for L'Aquila Earthquake (0.0086 m) which represents 58.25\%, the same values as of Scenario 1.

Overall, according to Fig. 11, which shows the curves of the maximum displacements per floor for the four seismic excitations, it can be seen that for Loma Prieta Earthquake, Scenario 1 presented the best performance in comparison to the uncontrolled structure. For the L'Aquila Earthquake, Scenario 2 can be considered as the best. For the Canterbury 
Earthquake, again the Scenario 1 can be considered as the best and for the Non-Stationary Artificial Earthquake, Scenario 2 is shown as the best.

\begin{tabular}{|c|c|c|c|c|c|c|c|c|}
\hline \multirow{3}{*}{ Story number } & \multicolumn{6}{|c|}{ Scenario 3- Percentage of response reduction } & \multirow{2}{*}{\multicolumn{2}{|c|}{$\begin{array}{c}\text { Non-Stationary Artificial } \\
\text { Earthquake }\end{array}$}} \\
\hline & \multicolumn{2}{|c|}{ Loma Prieta Earthquake } & \multicolumn{2}{|c|}{ L'Aquila Earthquake } & \multicolumn{2}{|c|}{ Canterbury Earthquake } & & \\
\hline & $\mathrm{D}_{\max }(\%)$ & ISD (\%) & $\mathrm{D}_{\max }(\%)$ & ISD (\%) & $\mathrm{D}_{\max }(\%)$ & ISD $(\%)$ & $\mathrm{D}_{\max }(\%)$ & ISD (\%) \\
\hline 1 & 50.75 & 50.75 & 59.38 & 59.38 & 47.22 & 47.22 & 64.96 & 64.96 \\
\hline 2 & 49.47 & 49.53 & 58.52 & 58.25 & 46.67 & 46.05 & 65.79 & 66.05 \\
\hline 3 & 49.49 & 49.14 & 57.55 & 55.26 & 45.77 & 44.88 & 66.06 & 66.67 \\
\hline 4 & 49.80 & 43.88 & 56.82 & 54.90 & 45.27 & 42.86 & 66.48 & 67.51 \\
\hline 5 & 50.17 & 41.67 & 56.53 & 58.10 & 44.29 & 40.00 & 66.82 & 68.34 \\
\hline 6 & 47.24 & 40.00 & 56.80 & 56.52 & 43.57 & 39.36 & 67.14 & 67.46 \\
\hline 7 & 42.84 & 37.00 & 57.24 & 53.49 & 42.67 & 40.00 & 67.46 & 66.01 \\
\hline 8 & 42.11 & 36.56 & 57.83 & 52.63 & 42.02 & 43.21 & 67.86 & 65.38 \\
\hline 9 & 41.57 & 36.47 & 57.44 & 52.24 & 41.58 & 47.22 & 68.22 & 65.18 \\
\hline 10 & 41.27 & 35.19 & 57.29 & 50.00 & 41.36 & 50.00 & 68.33 & 63.77 \\
\hline
\end{tabular}

Table 11: Percentage of reduction of the maximum displacements and interstory drifts of the structure under the four earthquakes records regarding uncontrolled structure to Scenario 3.
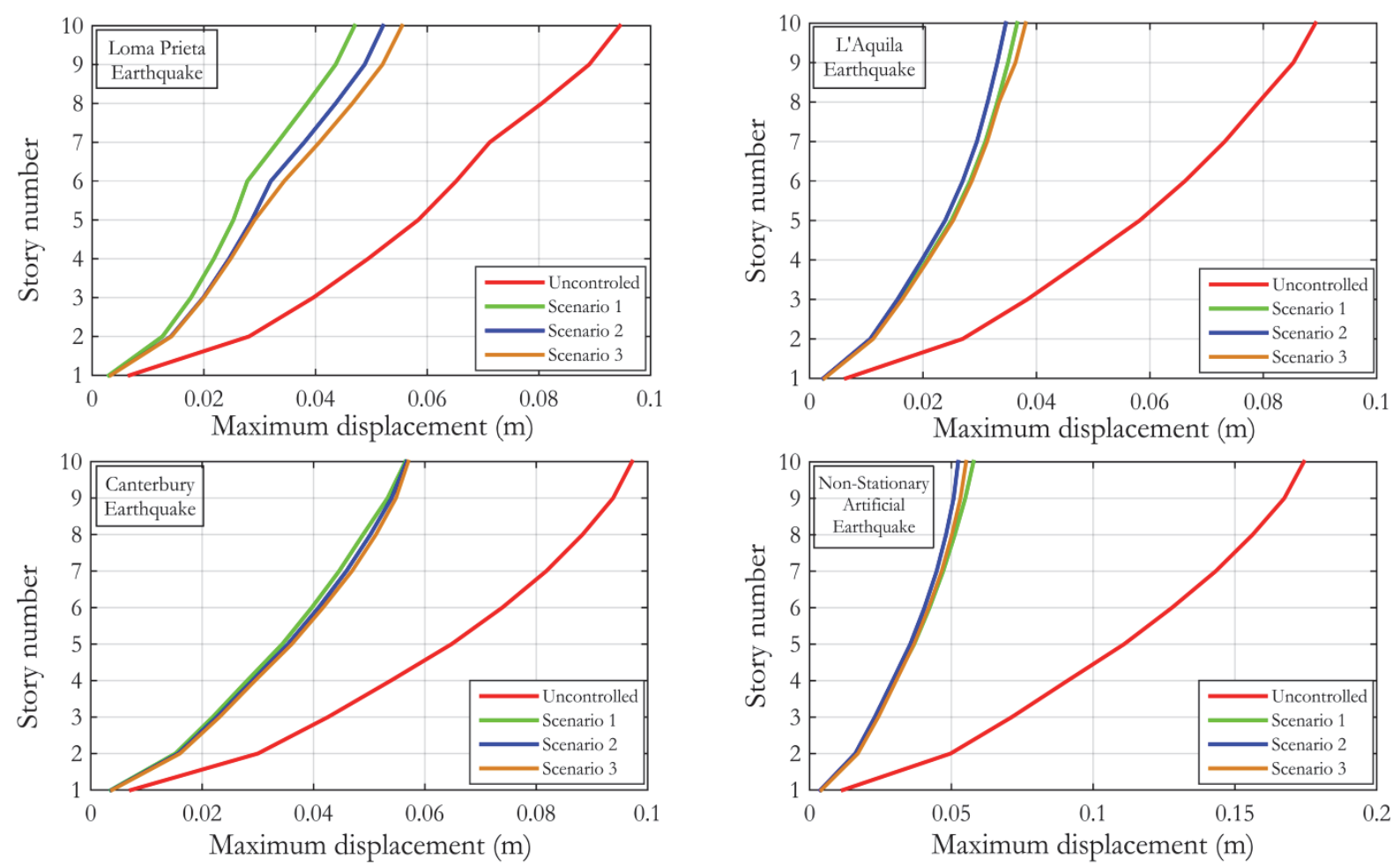

Figure 11: Maximum displacement per story for the structure under the four earthquakes records to each scenario. 

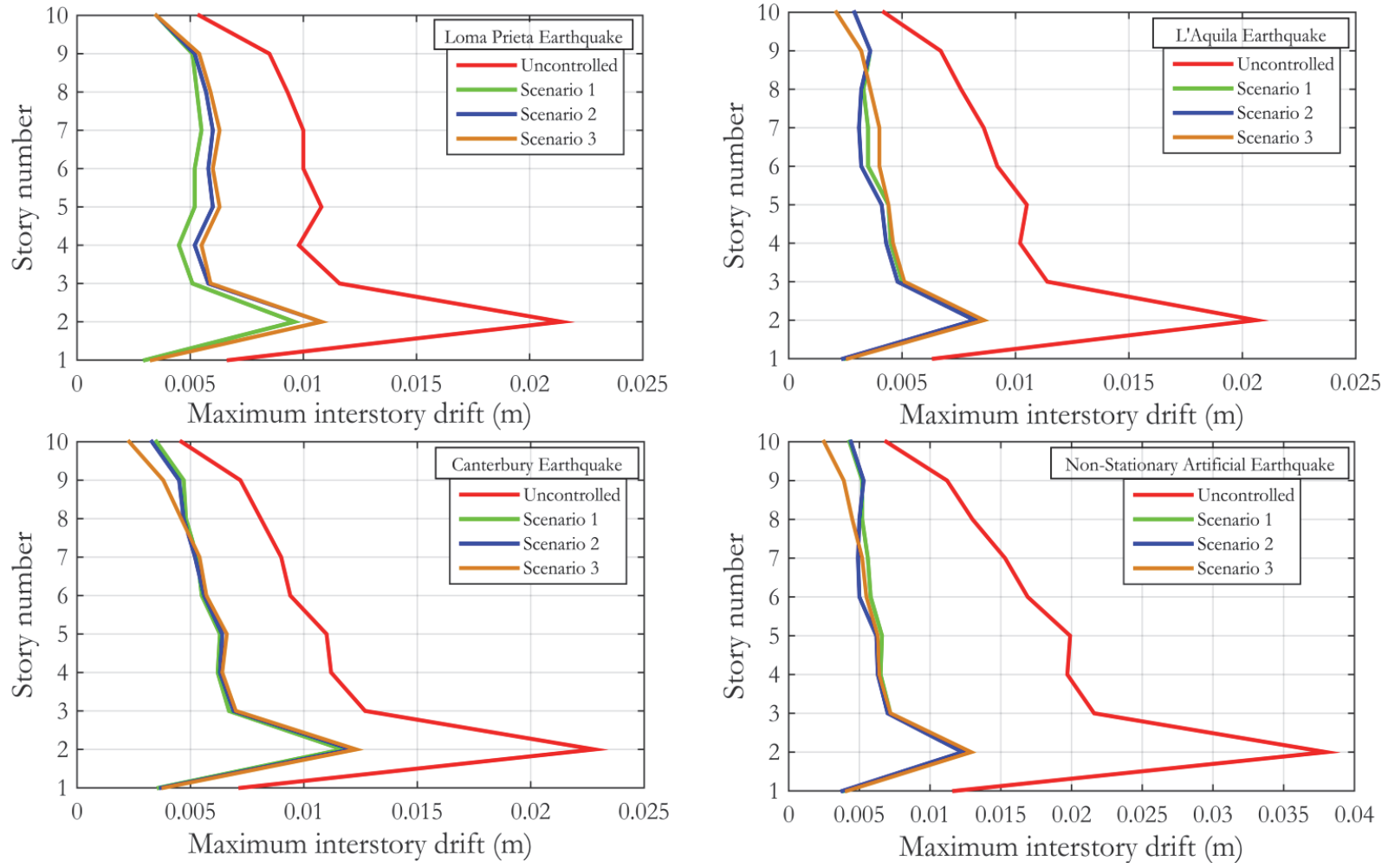

Figure 12: Maximum interstory drift for the structure under the four earthquakes records to each scenario.
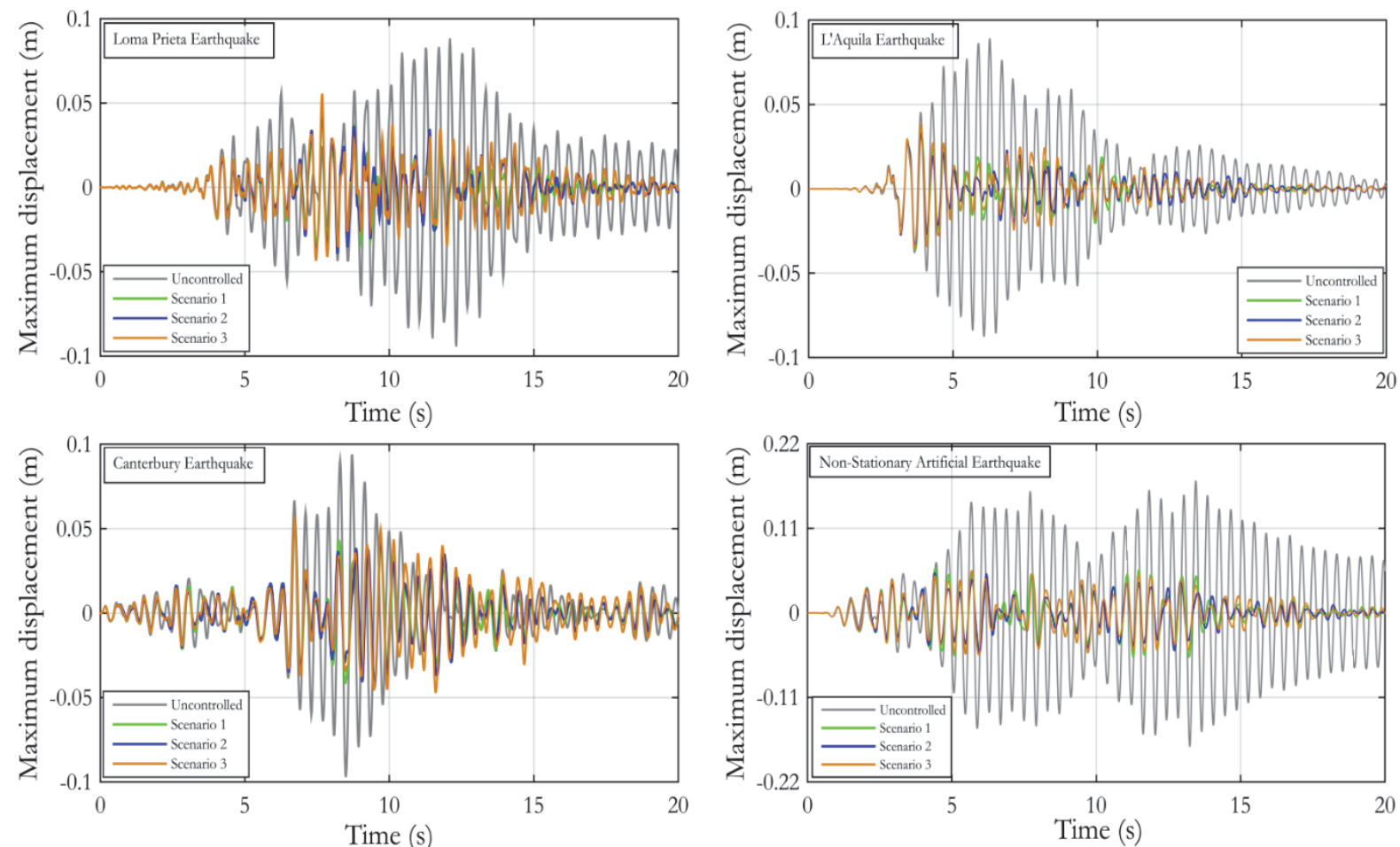

Figure 13: Displacement of the top of the building at node 63 considering the four earthquake records for uncontrolled structure and controlled scenarios. 
In Fig. 12 the maximum interstory drift of each floor is shown where, considering the $2^{\text {nd }}$ floor (which presented the largest interstory drift for each seismic excitation), regarding the Loma Prieta Earthquake, the Scenario 1 shows the best interstory drift reduction on this floor. For the L'Aquila Earthquake, Scenario 2 is considered as the best. For the Canterbury Earthquake, Scenario 1 is the best and for the Non-Stationary Artificial Earthquake Scenario 2 is shown as the best. Finally, in Fig. 13 the displacement at the top floor at node 63 is shown, which allows a better visualization of the reduction of displacements for each earthquake according to each scenario.

Overall, all scenarios are efficient in reducing the response of the top floor and the interstory drift for each seismic excitation considered. Considering the effectiveness control system, it is verified that Scenario 2 (4 TMDs horizontally arranged at the top) can be the best to reduce the top displacement and interstory drift for the $2^{\text {nd }}$ floor in relation to the worst case, which is the Non-Stationary Artificial Earthquake. In addition, regarding the economic aspect, this scenario would be the one which could generate lower spending in the implementation of the design, because the mass of one or the sum of the mass of multiple devices is always $3 \%$ of the structural mass and the values of the spring and damping constants should be evaluated. To Scenario 1 these values correspond to $1513880 \mathrm{~N} / \mathrm{m}$ and 32878 N.s/m, respectively. To Scenario 2 theses parameters, added, correspond to $1376656 \mathrm{~N} / \mathrm{m}$ and $22833 \mathrm{~N} . \mathrm{s} / \mathrm{m}$, respectively, and to Scenario 3 correspond to $31830151 \mathrm{~N} / \mathrm{m}$ and $10128 \mathrm{~N} . \mathrm{s} / \mathrm{m}$, respectively. Thus, scenario 2 can be considered as the best.

\section{CONCLUSIONS}

$\mathrm{T}$ his paper investigated the use of TMD for reduction of the maximum horizontal displacement at the top floor and the interstory drift of a steel building under four earthquakes, one of these being a resonant earthquake. The behavior of the uncontrolled structure was evaluated regarding the interstory drift limit given by ANSI/AISC 36016 code of the American Institute of Steel Construction [32] where it was verified that the building required a vibration control system in order to reduce the interstory drift to the imposed limits of the code. For this, three control scenarios are proposed, Scenario 1 with a single TMD at the top floor, Scenario 2 with 4 TMDs horizontally arranged at the top floor and Scenario 3 with maximum 10 TMDs vertically arranged along of the structure, one per floor.

To the optimization procedure, the WOA was utilized. To Scenarios 1 and 2, only spring and damping constants are optimized, while to Scenario 3, position and parameters of each TMD were optimized. By results obtained, it was verified that Scenario 1 presented the best reduction of maximum displacement at the top floor and of interstory drift for the Loma Prieta and Canterbury Earthquakes. Scenario 2 presented a better reduction of top displacement and interstory drift to the $2^{\text {nd }}$ floor to the L'Aquila and Non-Stationary Artificial Earthquakes, when compared to Scenario 1 and 3 . Overall, in this scenario the best reduction for interstory drift to the $2^{\text {nd }}$ floor was observed, $0.082 \mathrm{~m}$ to L'Aquila Earthquake. In Scenario 3, the best position and the optimal parameters are determined by an optimization procedure, and it resulted in four devices to be installed one per floor at the, $3^{\text {rd }}, 7^{\text {th }}, 8^{\text {th }}$ and $9^{\text {th }}$ floor. However, comparing this scenario to scenarios 1 and 2, it had slightly inferior performance. However, comparing only the results of this scenario, to the $2^{\text {nd }}$ floor the lowest value was obtained for L'Aquila Earthquake $(0.0086 \mathrm{~m})$ which represents $58.25 \%$, the same values of Scenario 1. Finally, overall, all scenarios studied were efficient to reducing the response of the top floor and the interstory drift correcting them to the imposed limits. However, the Scenario 2 can be considered as the best solution.

\section{ACKNOWLEDGMENTS}

he authors would like to acknowledge the Graduate Program in Civil Engineering of the Federal University of Rio Grande do Sul (PPGEC/UFRGS) and the financial support by CAPES and CNPq, Brazil.

\section{REFERENCES}

[1] Chandran, P. S. and Thampan, C. K. P. V. (2017). A Study on Vibration Control of Structures due to Seismic Excitation using Tuned Mass Damper, International Journal of Scientific \& Engineering Research, 8(11), pp. 105-112.

[2] Farshidianfar, A. and Soheili, S. (2013). Ant colony optimization of tuned mass dampers for earthquake oscillations of high-rise structures including soil-structure interaction, Soil Dynamics and Earthquake Engineering, 51, pp. 14-22. DOI: 10.1016/j.soildyn.2013.04.002. 
[3] Bekdaş, G. and Nigdeli, S. M. (2017). Metaheuristic based optimization of tuned mass dampers under earthquake excitation by considering soil-structure interaction, Soil Dynamics and Earthquake Engineering, 92, pp. 443-461. DOI: 10.1016/j.soildyn.2016.10.019.

[4] Brandão, F., Diógenes, A., Fernandes, J., Mesquita, E. and Betti, M. (2018). Seismic behavior assessment of a Brazilian heritage construction. Frattura ed Integrità Strutturale, 12(45), p. 14-32. DOI: 10.3221/IGF-ESIS.45.02.

[5] Symans, M. D. and Constantinou, M. C. (1999). Semi-active control systems for seismic protection of structures: a state-of-the-art review. Engineering Structures 21(6), p. 469-487. DOI: 10.1016/S0141-0296(97)00225-3.

[6] Lin, T. K., Hwang, J. S. and Chen, K. H. (2017). Optimal Distribution of Damping Coefficients for Viscous Dampers in Buildings. International Journal of Structural Stability and Dynamics, 17(4), 1750054, p. 19. DOI: $10.1142 / \mathrm{S} 0219455417500547$.

[7] Miguel, L. F. F., Fadel Miguel, L. F. and Lopez, R. H. (2018). Methodology for the simultaneous optimization of location and parameters of friction dampers in the frequency domain, Engineering Optimization, 50(12), pp. 21082122. DOI: $10.1080 / 0305215 X .2018 .1428318$.

[8] Ribakov, Y. and Agranovich, G. (2011). Control of structural seismic response by a limited set of active dampers. The Structural Design of Tall and Special Buildings 20(5), p. 594-611. DOI: 10.1002/tal.684.

[9] Yang, DH., Shi, JH., Lee, HW., Kim, SK. and Moon, KK. (2017). Active vibration control of structure by Active Mass Damper and Multi-Modal Negative Acceleration Feedback control algorithm. Journal of Sound and Vibration, 392, pp. 18-30. DOI: 10.1016/j.jsv.2016.12.036.

[10] Shih, MH. and Sung, WP. (2014). Development of semi-active hydraulic damper as active interaction control device to withstand external excitation, Sadhana, 39, pp. 123-138. DOI: 10.1007/s12046-013-0196-3.

[11] Ribakov Y. and Agranovich, G. (2015). Using a limited set of MR dampers for improving structural seismic response. Structural Control and Health Monitoring, 22(4), p. 615-630. DOI: 10.1002/stc.1711.

[12] Kaveh, A., Mohammadi, S., Hosseini, O. K., Keyhani, A. and Kalatjari, V.R. (2015). Optimum parameters of tuned mass dampers for seismic applications using charged system search, Iranian Journal of Science and Technology Transactions of Civil Engineering, 39(C1), pp. 21-40. DOI: 10.22099/ijstc.2015.2739.

[13] Miguel, L. F. F., Fadel Miguel, L. F. and Lopez, R. H. (2016). Simultaneous optimization of force and placement of friction dampers under seismic loading, Engineering Optimization, 48(4), pp. 582-602. DOI: $10.1080 / 0305215 X .2015 .1025774$.

[14] Etedali, S. and Rakhshani, H. (2018). Optimum design of tuned mass dampers using multi-objective cuckoo search for buildings under seismic excitations, Alexandria Engineering Journal, 57(4), pp. 3205-3218.

DOI: 10.1016/j.aej.2018.01.009.

[15] Chen, G. and Wu, J. (2001). Optimal placement of multiple tune mass dampers for seismic structures, journal of Structural Engineering, 127(9), pp. 1054-1062. DOI: 10.1061/(ASCE)0733-9445(2001)127:9(1054).

[16] Gwalani, P. and O. R. Jaiswal, O. R. (2017). Vibration Control using Tuned Mass Damper, International Journal of Engineering Research in Mechanical and Civil Engineering (IJERMCE), 2(3), pp. 315-319. DOI: $01.1617 / \mathrm{vol} /$ iss3/pid32491.

[17] Rahmani, H. R. and Könke, C. (2019). Seismic Control of Tall Buildings Using Distributed Multiple Tuned Mass Dampers, Advances in Civil Engineering, ID 6480384, p. 19. DOI: 10.1155/2019/6480384.

[18] Vellar, L. S., Pérez, S. P. O., Miguel, L. F. F., and Fadel Miguel, L. F. (2019). Robust Optimum Design of Multiple Tuned Mass Dampers for Vibration Control in Buildings Subjected to Seismic Excitation, Shock and Vibration, ID 9273714, p. 9. DOI: $10.1155 / 2019 / 9273714$.

[19] Osaba, E and Del Ser, J. (2018). Introductory Chapter: Nature-Inspired Methods for Stochastic, Robust, and Dynamic Optimization, In: Nature-inspired Methods for Stochastic, Robust and Dynamic Optimization, London: IntechOpen, pp. 1-6. DOI: 10.5772/intechopen.78009.

[20] Kennedy, J. and Eberhart, R.C. (1995). Particle swarm optimization. International Conference on Neural Networks, Perth, Australia, DOI: 10.1109/ICNN.1995.488968.

[21] Dorigo, M., Maniezzo, V. and Colorni, A. (1996). The ant system: optimization by a colony of cooperating agents, IEEE Transactions on Systems, Man, and Cybernetics, Part B (Cybernetics), 26(1), pp. 29-41.

DOI: $10.1109 / 3477.484436$.

[22] Geem, Z. W., Kim, J. H. and Loganathan, G.V. (2001). A new heuristic optimization algorithm: Harmony Search. Simulation, 76(2), pp. 60-68. DOI: 10.1177/003754970107600201.

[23] Yang, X-S. (2009). Firefly algorithms for multimodal optimization. In: Stochastic algorithms: foundations and applications, London: SAGA 2009, Lecture notes in computer sciences, 5792, pp. 169-78.

DOI: 10.1007/978-3-642-04944-6_14. 
[24] Mirjalili, S. and Lewis, A. (2016). The whale optimization algorithm, Advances in Engineering Software, 95, pp. 51-67. DOI: 10.1016/j.advengsoft.2016.01.008.

[25] Kaveh, A. and Talatahari, S. (2010). A novel heuristic optimization method: charged system search, Acta Mechanica, 213, pp. 267-289. DOI: 10.1007/s00707-009-0270-4.

[26] Yang, X.-S and Deb, S. (2009). Cuckoo search via Lévy flights. World Congress on Nature \& Biologically Inspired Computing, Coimbatore, India. DOI: 10.1109/NABIC.2009.5393690.

[27] Fadel Miguel, L. F., Lopez, R. H., Miguel, L. F. F. and Torii, A. J. (2016). A novel approach to the optimum design of MTMDs under seismic excitations, Structural Control and Health Monitoring, 23(11), pp. 1290-1313. DOI: $10.1002 /$ stc. 1845 .

[28] Nelder, J.A. and Mead, R. (1965). A simplex method for function minimization, The Computer Journal, 7(4), pp. 308313. DOI: $10.1093 / \mathrm{comjnl} / 7.4 .308$.

[29] Bozer, A. and Özsarıyldız, S. S. (2017). Free parameter search of multiple tuned mass dampers by using artificial bee colony algorithm, Structural Control and Health Monitoring, 25(2), pp. 1-13. DOI: 10.1002/stc.2066.

[30] Karaboga, D. (2005). An idea based on honey bee swarm for numerical optimization. Technical Report TR06. Erciyes University, Engineering Faculty, Computer Engineering Department, Kayseri/Türkiye.

[31] Gonçalves, M. S., Lopez, R. H. and Fadel Miguel, L. F. (2015). Search group algorithm: a new metaheuristic method for the optimization of truss structures, Computers \& Structures, 153, pp. 165-184. DOI: $10.1016 /$ j.compstruc.2015.03.003.

[32] American Institute of Steel Construction. (2016). Specification for Structural Steel Buildings ANSI/AISC 360-16. Chicago, Illinois: AISC, pp. 1-677.

[33] Ohtori, Y., Christenson, R.E., Spencer Júnior, B. F. and Dyke, S. J. Benchmark control problems for seismically excited nonlinear buildings, Journal of Engineering Mechanics, 130(4), pp. 366-385. DOI: 10.1061/(ASCE)0733-9399(2004)130:4(366).

[34] Center for Engineering Strong Motion Date. (n.d). CESMD Strong-Motion Data Set. Available at: https://strongmotioncenter.org/cgi-bin/CESMD/archive.pl.

[35] Kanai, K. (1961). An empirical formula for the spectrum of strong earthquake motions, Bulletin Earthquake Research Institute, University of Tokio, 39, pp. 85-95.

[36] Tajimi, H. (1960). A statistical method of determining the maximum response of a building structure during an earthquake. $2^{\text {nd }}$ World Conference on Earthquake Engineering, Tokyo, Japan, 11-18 July.

[37] Jennings, P.C., Housner, G.W. and Tsai, N.C. (1968). Simulated earthquake motions. A report on research conducted under a grant from the National Science Foundation. California Institute of Technology, Pasadena. pp. 1-55.

[38] Shinozuka, M. and Jan, C.M. (1972). Digital simulation of random processes and its applications, Journal of Sound and Vibration, 25(1), pp. 111-128. DOI: 10.1016/0022-460X(72)90600-1. 